\title{
Secular Fertility Declines, Baby Booms and Economic Growth: International Evidence
}

\author{
Robert Tamura Curtis Simon*
}

February 15, 2010

\begin{abstract}
We present a model capable of explaining 200 years of declining fertility, 200 years of rising educational achievement and a significant Baby Boom for the United States and twenty other industrialized market countries. We highlight the importance of secularly declining young adult mortality risk for producing secularly declining fertility and a sudden decline in housing costs after the end of the Second World War, but ending by 1970. In addition we introduce a new puzzle to the profession. Given the magnitude of the Baby Boom, roughly equal to fertility in 1900 for many of these countries, why did schooling of the Baby Boom cohorts not fall to the 1900 level of their predecessors? In fact, not only do they not fall, but their schooling levels are higher than previous cohorts. Using a quantitative model we are able to identify the magnitude of the reduction in costs of education necessary to explain this paradoxical increase in schooling. We find empirical support for these cost reductions.
\end{abstract}

In this paper we present a model which we view as an identification exercise. Principally we are interested in identifying the forcing variables for secularly declining fertility in the United States throughout the past 200 years, as well as the Baby Boom. The Baby Boom was a dramatic deviation from the securlar trend in children ever born by women. Prior to the Baby Boom the typical American woman had about 2.4 children over her reproductive life. At the peak of the Baby Boom, the typical American woman had 3.2 children over her reproductive life. At the end of the Baby Boom the typical American woman had 2 children over her reproductive life.

Recent work by Greenwood, et. al. (2005) provides one explanation for the secular decline in fertility and the Baby Boom. They identify rising market productivity as the cause for the secular decline in fertility. A once and for all increase in household productivity caused the Baby Boom to occur in the United States and in other western countries. In particular they argue that the introduction of modern appliances in the household dramatically lowered the cost of fertility. Adoption of mechanical washing machines, refrigerators, stoves and ovens would lower the cost of household production. ${ }^{1}$ However a recent paper by Bailey and Collins (2006) shows that the Greenwood, et.al. hypothesis has other difficulties.

${ }^{*}$ Clemson University and Clemson University and the Atlanta Federal Reserve Bank We thank the seminar participants at the Midwest Macroeconomics Meetings at Washington University, Florida State University, IUPUI and the Conference on Open Macroeconomics and Development in Aix en Provence for helpful comments and suggestions. We remain responsible for all remaining errors. The views expressed here do not represent the views of the Federal Reserve, nor the Federal Reserve Bank of Atlanta.

${ }^{1}$ One would also have to believe that the further improvements on these appliances are generally neurtal towards fertility, or at least too small to overcome the rising return to labor market participation of women. The introduction of radio, television and particularly color television appear to serve as substitutes for children, in terms of their timing. 
Much of the effect identified by Greenwood, et. al. requires that the household be wired for electricity. Using a data set on electricity usage in households, they find little correlation between electrification and fertility. Additionally they show that the Amish had the same Baby Boom as others in the United States, even though they do not use modern appliances or electricity. In this paper we identify secularly declining young adult mortality, as in Tamura (2006), as the cause for declining fertility. However unlike Greenwood, et. al., we identify falling price for space as the principal cause of the Baby Boom. We have in mind the dramatic expansion in the suburban land area available for housing as a result of the interstate highway system in the United States as the cause of a reduction in housing costs. In addition we require changes in educational efficiency in order to explain the secular trend in completed years of schooling. The model does an excellent job of fitting the data for fertility as well as years of schooling, and serves to identify the magnitude of shocks to housing costs and educational efficiencies.

\section{$1 \quad$ Model}

In this section we present a model with parental choice of fertility, $x$, human capital of their children, $h^{\prime}$, a composite consumption good, $c$, and space, $S .^{2}$ Parents choose the number of children to have in an environment of young adult mortality. Parental preferences are:

$$
\alpha\left(c_{t}^{\psi} S_{t}^{1-\psi}\right)^{\varphi}\left[\left(1-\delta_{t}\right) x_{t}-a\right]^{1-\varphi}+\Lambda\left(Z h_{t+1}\right)^{\varphi}-\frac{Z^{\varphi} \beta \delta_{t}^{\nu_{t}}}{\left[\left(1-\delta_{t}\right) x_{t}-a\right]\left(1-\delta_{t}\right)^{\varepsilon}},
$$

where $\nu$ is a time varying preference parameter that becomes constant by $1950 .^{3}$ We assume that the young adult mortality rate is $\delta$. Further we assume that expected net fertility is what parents care about, $(1-\delta) x-a, a \geq 0$. Thus we model the parental fertility choice similar to Jones (2001), where elasticity of substitution of net expected fertility with human capital investments is greater than 1 . This in turn exceeds the elasticity of substitution between net expected fertility and space, 1 . The final term, with $\varepsilon>0$, in the preferences captures something like a precautionary demand for fertility as in Kalemli-Ozcan (2002, 2003) and Tamura (2006). Notice that it also depends on the level of total factor productivity. The more productive the economy, the more costly young adult mortality is from the perpsective of utility. With falling young adult mortality rates, which in the limit reach 0 , the final term in preferences disappears.

The budget constraint facing the typical parent is given by:

$$
p c_{t}+r_{t} x_{t} S_{t}=Z h_{t}\left[1-x_{t}\left(\theta+\kappa_{t} \tau_{t}\right)\right]
$$

where $Z$ is the constant total factor productivity in production, $\theta$ is the time cost of rearing children, $\tau$ is the time spent educating children, $\kappa$ is the time efficiency of education time, $p$ is the price of consumption and $r$ is the price per unit of space. ${ }^{4}$ Finally we assume that the human capital accumulation technology

\footnotetext{
${ }^{2}$ The results of the numerical solution for the United States were used in Murphy, Simon and Tamura (2008) in order to identify the relevant price of space. That paper compared the model solution for the required time series on price of space with measures of population density.

${ }^{3}$ In the appendix we indicate via the country specific graphs what the time series for $\nu$ is. For almost all countries the stationary value of $\nu$ is the same, .40. In an earlier version, as well as in Murphy, Simon and Tamura (2008) we had preferences that included an endogenous time varying total factor productivity in each of the three terms. However we have been able to simplify the model and eliminate the need for endogenous total factor productivity, hence $\mathrm{Z}$ is constant.

${ }^{4}$ Alternatively we could have specified the first term in preferences as depending on a composite of space, $S$, and all other consumption goods, $c$, and net expected fertility: $\alpha X^{\varphi}[(1-\delta) x-a]^{\lambda-\varphi}$, where $X=\left\{\sigma c^{\frac{1}{\rho}}+(1-\sigma) S^{\frac{1}{\rho}}\right\}^{\rho}$. If $\rho$ were
} 
is given by: ${ }^{5}$

$$
h_{t+1}=A \bar{h}_{t}^{\rho} h_{t}^{1-\rho} \tau_{t}^{\mu}
$$

This accumulation technology is from Tamura $(1991,2006)$. We assume that the US is the frontier human capital country, so that the US $h_{t}=\bar{h}_{t}$ for all countries. ${ }^{6}$ Substituting (3) and (2) into (1) and differentiating produces the two Euler conditions determining optimal choices of fertility and human capital investments:

$$
\begin{aligned}
\frac{\partial}{\partial \tau} \quad: \quad \psi \varphi \alpha c_{t}^{\psi \varphi-1} S_{t}^{(1-\psi) \varphi}\left[\left(1-\delta_{t}\right) x_{t}-a\right]^{1-\varphi} \frac{Z h_{t} x_{t} \kappa_{t}}{p}=\mu \varphi Z^{\varphi} A^{\varphi}\left(\bar{h}_{t}^{\rho} h_{t}^{1-\rho}\right)^{\varphi} \tau_{t}^{\mu \varphi-1} \\
\frac{\partial}{\partial x} \quad: \quad \psi \varphi \alpha c_{t}^{\psi \varphi-1} S_{t}^{(1-\psi) \varphi}\left[\left(1-\delta_{t}\right) x_{t}-a\right]^{1-\varphi} \frac{w h_{t}\left[\theta+\kappa_{t} \tau_{t}\right]+r_{t} S_{t}}{p} \\
\quad=(1-\varphi) \alpha c_{t}^{\psi \varphi} S_{t}^{(1-\psi) \varphi}\left[\left(1-\delta_{t}\right) x_{t}-a\right]^{-\varphi}\left(1-\delta_{t}\right)+\frac{Z^{\varphi} \beta \delta_{t}^{\nu t}}{x_{t}^{2}\left(1-\delta_{t}\right)^{\varepsilon}} \\
\frac{\partial}{\partial S} \quad: \quad \psi \varphi \alpha c_{t}^{\psi \varphi-1} S_{t}^{(1-\psi) \varphi}\left[\left(1-\delta_{t}\right) x_{t}-a\right]^{1-\varphi} \frac{r_{t} x_{t}}{p} \\
\quad=\alpha(1-\psi) \varphi c_{t}^{\psi \varphi} S_{t}^{(1-\psi) \varphi-1}\left[\left(1-\delta_{t}\right) x_{t}-a\right]^{1-\varphi}
\end{aligned}
$$

We can solve for $c_{t}$ as a function of $S_{t}$ and $x_{t}$. This produces:

$$
c_{t}=\left(\frac{\psi}{1-\psi}\right) \frac{r_{t} x_{t} S_{t}}{p}
$$

Substituting this into the budget constraint produces:

$$
r_{t} x_{t} S_{t}=(1-\psi) Z h_{t}\left[1-x_{t}\left(\theta+\kappa_{t} \tau_{t}\right)\right]
$$

Substituting this back into the objective function produces the following problems facing the household:

$$
\max _{x_{t}, \tau_{t}}\left\{\begin{array}{c}
\alpha\left(\frac{\psi}{p_{t}}\right)^{\psi \varphi}\left(\frac{1-\psi}{r_{t} x_{t}}\right)^{(1-\psi) \varphi}\left(Z h_{t}\left[1-x_{t}\left(\theta+\kappa_{t} \tau_{t}\right)\right]\right)^{\varphi}\left[\left(1-\delta_{t}\right) x_{t}-a\right]^{1-\varphi} \\
+\Lambda\left(Z h_{t+1}\right)^{\varphi}-\frac{Z^{\varphi} \beta \delta_{t}^{\nu}}{\left(1-\delta_{t}\right)^{\varepsilon}}\left[\left(1-\delta_{t}\right) x_{t}-a\right]^{-1}
\end{array}\right\}
$$

What is most interesting to us is the decline in the fertility rate with the decline in young adult mortality, $\delta$, as well as the relationship between the price of space, $r$, and fertility. Due to the interaction of fertility with both space as well as human capital investments, the budget constraint facing the typical parent is not convex. As a consequence, the comparative static exercise does not lead to any nice analytical results. We thus utilize numerical solution methods to examine the interaction of the precautionary demand for fertility and human capital investments in the long term. Also the numerical solutions presented below indicate the requisite decline in the price of space in order to induce a baby boom. Thus in the numerical solutions, we produce the secular decline in fertility arising from the rising survival rate, or falling mortality rate, as well as the rising levels of human capital investment. Furthermore one possible mechanism of the

negative, so that goods were stronger complements than the Cobb-Douglas case examined here.

${ }^{5}$ In the numerical solutions we allow $\mu$ to vary across countries. Within a country $\mu$ is constant. Holding $\kappa$ constant, changes in $\mu$ imply differential efficiency in converting study time to human capital. Since the proportion of the first period of life spent in school is a fraction less than 1, increasing $\mu$ implies lower productivity in schooling holding time in school fixed.

${ }^{6}$ For the UK, we backsolved the growth rate of the US human capital stock and used that as the spillover value for the period $1600-1800$. 
baby boom is the falling price of space. We are able to replicate the broad pattern of fertility as well as human capital investment.

We also use the parameter $\kappa$ to produce the appropriate secular rise in human capital investment time. We use information on years of schooling in the labor force for the US from Turner, Tamura, Mulholland and Baier, (2006), as a measure of $\tau$. We assume that a period length is 40 years, so that $40 \tau_{t}$ is the years of schooling for the typical individual born in year $t .^{7}$ In the international comparisons, we use data from Baier, Dwyer and Tamura (2006) as well as Baier, Devereux, Dwyer and Tamura (2008) to fit years of schooling, fertility, young schooling, output per worker.There is a strong quality and quantity tradeoff in the model. The solutions show that the current low rate of fertility in these countries are often so low that they imply counterfactual schooling attainment. Furthermore the baby booms in the countries typically imply dramatic reductions in schooling for that cohort as well as schooling in the population. Thus we used the efficiency of time for schooling, $\kappa$, as a means to control for these counterfactual schooling levels.

\subsection{Stationary Values and Numerical Solutions}

In this section we analyze the stationary solution as well as present numerical solutions. We assume that the stationary fertility rate is 1 . Examining the Euler equation with respect to fertility when mortality risk is 0 , we can produce the parameter restriction on $a$ as a function of parameters and the stationary human capital investment rate, $\bar{\tau}$ :

$$
a=1-\frac{(1-\varphi)(1-[\theta+\bar{\tau}])}{\varphi(1-\psi(1-[\theta+\bar{\tau}]))}
$$

The stationary solution also produces the following connection between the rate of TFP growth, and staionary values of investment rates, rental price of space, the price of consumption and parameters.:

$$
1=\frac{\Lambda \mu\left[A r^{1-\psi} p^{\psi}\right]^{\varphi}(1-\theta-\bar{\tau})^{1-\varphi}}{\alpha\left[\psi^{\psi}(1-\psi)^{1-\psi}\right]^{\varphi}(1-a)^{1-\varphi} \bar{\tau}^{1-\mu \varphi}},
$$

where the left hand side is stationary under a balanced growth path. Under these parameter restrictions and convergence of mortality risk to 0, perhaps due to human capital accumulation as in Tamura (2006), the long run fertility rate and human capital investment rate will be $x=1, \tau=\bar{\tau}$.

What follows is the generation of time series on total fertility rates, years of schooling, consumption and space. We present these results in comparison with the actual data, under varying assumptions. The model solutions presented result from numerically solving the Euler equation for $\tau_{t}$ for a range of possible values of fertility, $x_{t}$. The resulting solutions are compared and the one generating the highest utility is selected as optimal. $^{8}$

Before continuing we discuss how we calculated our measure of young adult mortality risk, $\delta$. We used the actual time series history on probability of dying between the ages of 1 and $35, d_{1,35}$ to produce our measure of $\delta$. Specifically we used data from Tamura (2006) on infant mortality, $m$, and the probability

\footnotetext{
${ }^{7}$ In the numerical solutions we assume that the nonlinear budget constraint provides the possibility that fertility may be at a corner, as in Ehrlich and Lui (1991). Thus our algorithm allows for this, although in practice all choice variables are interior solutions.

${ }^{8}$ We use this method in order to allow for the possibility of corner solutions. Since the budget constraint is not linear, the budget set is not convex, and hence it is plausible that fertility might head either towards a maximum level, i.e. $x=\frac{1}{\theta}$, or a minimal level, i.e. $x=a+\zeta$, for arbitrarily small $\zeta$.
} 
of dying between the ages of 1 and $35, d_{1,35}$, to construct a forecast probability of dying between the ages of 1 and 35. We do not assume that individuals have perfect foresight, instead we assume that they made rational forecasts of the probability of dying between the ages of 1 and 35 prior to 1900 . We regressed the $\log$ of the probability of dying between the ages of 1 and 35 for years prior to 1900 on a time trend. We then used the forecast values, $p_{1,35}$ as our measure of the perceived risk of dying between 1 and 35 . We then ran the regression of log of the probability of dying between the ages of 1 and 35 for $1900-1949$ on a time trend. We then used the forecast values as our measure of the preceived risk of dying between 1 and 35 for years 1900 - 2000. We did this because the introduction of pennicillin in medical use was a dramatic change in the probability of dying of infectious diseases. We do not assume that the typical individual knew about pennicillin at all. By 2000 the deviation of the forecast from the actual probability is quite small. We did the same thing for infant mortality to produce our forecast of infant mortality, $\widehat{m}$. Thus our measure of the relevant young adult mortality risk is $\delta$ :

$$
\delta=p_{1,35}+\frac{\widehat{m}}{3}
$$

As can be seen, we downweight the effect of infant mortality by $\frac{1}{3}$. This is due to the fact that an infant death is less costly to replace than a death of a child say at age 12. This for the obvious reason that after 12 years a substantial amount of human capital investment could have been made, a substantial level of support has been delivered, and perhaps even more importantly, a large proportion of a woman's child bearing potential has disappeared. For if a child born when a woman was 15 dies at age 12, she is now 27, with only 17 years of reproductive life remaining. Ideally one would consider the relative price of mortality at 2 years of age versus say 12 years of age to construct an economically relevant young adult mortality in a sequential fertility-human capital investment model. Table 1 below presents the fit of the model with various assumptions on parameters, $\nu$, preferences, $r$, the rental price of space, and $\kappa$ the cost of teaching time. There are four panels in Table 1. Starting in the upper left hand corner of the table, we present the regressions results for fertility. The top right hand corner presents the regression results for schooling. The bottom left hand corner presents the results for log income per worker, and the bottom right hand corner presents the results for schooling of the young cohort. The data for fertility come from Tamura (2006). The remaining data for schooling, both average and young cohort, and real output per worker come from Tamura, Devereux, Dwyer and Baier (2010). In the column labeled base, the model assumes only a time varying mortality rate. Thus the typical regression run was:

$$
y_{t}=\alpha+\beta x_{t}
$$

where $y_{t}$ is the year $t$ observation on either children ever born or average years of schooling in the labor force, etc.; $x_{t}$ is the year $t$ observation from the model on children ever born or the average years of schooling in the labor force between the ages of 20 to 65 , etc. Under the null hypothesis that the model fits the data, $\alpha=0$, and $\beta=1$. The row marked with $F$ provides the $F$ statistic on the joint test of these hypotheses.

In order to illustrate better these results, the figure below contains the data and the model solutions for children ever born and years of schooling in the labor force for the base case and the time varying $\left(r_{t}, \kappa_{t}\right)$ case contained in Table 1. There are clearly three major features of the children ever born data: (1) the secular decline from 7 children born over a woman's reproductive life in 1800 to 2 children born by the end of the period, (2) the baby boom for women in the years 1946-1964, (3) the mini bulge in fertility for women 
born between 1840-1860. The base model, picks up on the secular decline in fertility arising from the secular decline in $\delta$. As one moves across the columns of Table 1, we allow for time varying parameters in the model. We sequentially add time varying parameters. In other words as one moves to the right of the table we keep changing time varying parameters. Thus we keep allowing more parameters to vary. First tastes, then we have tastes and rents, finally tastes, rents and time efficiency of schooling. The first column after the base case is time varying taste parameter $\nu_{t}$ which is the exponent on the mortality risk in the precautionary demand set-up. The next is time varying tastes and rental price of space, $\left(\nu_{t} r_{t}\right)$. The last column allows all to vary, $\left(\nu_{t} r_{t}, \kappa_{t}\right)$. In all four panels of Table 1, the full model provides the best fit with the data for 21 countries. This is true based on improvements in the goodness of fit, $\bar{R}^{2}$, and the closeness of the slope coefficient to 1 , and the constant to 0 . In two of the four regressions, the $\mathrm{p}$ value on the null of $\beta=1$ and $\alpha=$ 0isgreaterthan.05.Thusinhal fof thecasesweacceptthenullthatthatthemodelsolutionsandthedataarestatisticallyidentical.

In Figures 1-21, we only present the data on and the solutions to fertility, schooling, real output per worker and young cohort schooling. We present all four cases, from the base case (no time varying parameters), preferences (time varying $\nu_{t}$ ), preferencesandtimevaryingrent $\left(\nu_{t}, \mathrm{r}_{t}\right)$ and the full time varying parameter model, $\nu_{t},\left(r_{t}, \kappa_{t}\right)$. By and large the results reproduce the Baby Boom in each country's data, but do not fit the years of schooling data at all. Notice as well that the base model clearly picks up the secular increase in schooling in the labor force. Clearly however the model dramatically over predicts years of schooling. This arises due to the below replacement rate of fertility in the base model. The addition of time varying rental rates for space, $r_{t}$ produces the standard quality-quantity tradeoff of Becker and Lewis (1973).

After Figure 1, the entries are alphabetic by country name: Australia, Austria, Belgium, Canada, Denmark, Finland, France, Germany, Greece, Ireland, Italy, Japan, Netherlands, New Zealand, Norway, Portugal, Spain, Sweden, Switzerland, and the United Kingdom. ${ }^{9}$ In all of the cases, the base model generally can pick up the time series of fertility with the exception of the Baby Boom experiences. As with the case for the United States, the introduction of time varying price per unit of space to produce a Baby Boom, dramatically alters the years of schooling in the labor force. Thus the need for $\nu_{t},\left(r_{t}, \kappa_{t}\right)$ in order to produce the secular rise in schooling in each of these countries. Notice that for almost all of the countries there is if anything, an acceleration in accumulation of years of schooling that accompanies their Baby Boom. It is fair to say that the Baby Boom experiences in the United States as well as these other industrialized market countries arose from shocks to the total demand for children. This increase in demand was for both quantity and quality, so that the typical quality-quantity tradeoff did not occur during this cycle.

The base United States case that is assumed is that there are constant prices for $(S, c),(r=1.285531, p=$ 1.002461). We present the time series of price of space needed in the model to reproduce the Baby Boom in the US. We compare it with the average population density of the US. ${ }^{10}$ This is contained in Figure 22. Curiously the population density of the US has been constant since 1980, at values lower than those that produced the Baby Boom, and yet US fertility did not remain high.

\footnotetext{
${ }^{9}$ These are the same rich countries that were modeled in Tamura (2006). The only exception is the exclusion of Korea. Korean data on fertility and mortality only goes back to 1950 and the data is one of monotone decline in fertility. South Korea does not have a Baby Boom in their post war period. The other countries in Tamura (2006), India, China, and the regions of Latin America, Central and Eastern Europe and the rest of Asia do not have any Baby Boom cycles either. The data to fit these series comes from both Tamura (2006) and Tamura, Devereux, Dwyer and Baier, (2009).

${ }^{10}$ We computed this by calculating the population density by county, and then weighting each county by the population in the county. Thus we are measuring the average number of people an individual is surrounded by, and not the average number of people per mile.
} 
In the Appendix, we present the graphs of the time series of preference parameters, $\nu_{t}$, the rental price of space, $r_{t}$, and the cost of schooling $\kappa_{t}$. In all cases the cost of schooling must fall dramatically during the Baby Boom in order to fit the observed time series of schooling of the Baby Boom cohort and the average schooling in the population. This is the first time any paper has identified this phenomena.

Recall that the total expenditures on schooling of the next generation, $E_{t}$ are given by:

$$
E_{t}=Z h_{t} x_{t} \kappa_{t} \tau_{t}
$$

Total income is given by $Z h_{t}$, so expressed as expenditures per student, $e_{t}$, we have:

$$
e_{t}=\kappa_{t} \tau_{t}
$$

Thus if we take the share of GDP spent on education, both public and private, and divide by the number of students and multiply by population, we get something analogous to $e_{t}$. If we divide $e_{t}$ by an estimate of the length of time of schooling, tau , we can identify $\kappa_{t}$. Luckily for us, we do have already estimates of the length of schooling, $\tau_{t}$, schooling of the young cohort. In order to express this as a share of lifetime, we divided this schooling length by 80 years of expected life. Thus the education data provides us with measures of $e_{t}$ and $\kappa_{t}$. In Table 2 we present evidence on the decline of schooling cost during the Baby Boom for both measures of education expenditures. We further provide evidence for the US separately, as we have the most data for the US, almost covering annually the Baby Boom years of 1946-1964. ${ }^{11}$ As with the previous goodness of fit regressions, we run

$$
y_{t}=\alpha+\beta x_{t}
$$

where $y_{t}$ is either $\kappa_{t} \tau_{t}$ or $\kappa_{t}$, and $x_{t}$ is either $\kappa_{t}^{\text {model }} \tau_{t}^{\text {model }}$ or $\kappa_{t}^{\text {model }}$. The evidence from Table 2 is broadly supportive. For the US, the results are very strongly positive. Our model solutions for both $\kappa_{t} \tau_{t}$ expenditures per pupil, and cost of schooling $\kappa_{t}$ are quite close to the observed data. For all 21 countries the model's solutions are positively correlated with the data, although they do not fit the data as well as the US. Still in all eight specifications, the model solutions are significantly positively correlated with the actual data.

\section{School efficiency}

School efficiency in the model is separated from the diffusion of knowledge arising from the spillover parameter, $\rho$. In the solutions we assumed a value of $\rho=.40$. However countries can differ in their efficiency in transforming school time into human capital, via $\mu$. In order to fit the growth rate of income we used $\mu$ as a major source of the cross country differences. Since the United States had the smoothest income process by far, and since it was generally the most productive country in the 1800 start of the data, most countries would have had a $\mu$ smaller than the United States, except for the spillover effect of human capital. This is contained in Table 3. This is very close to the work of Schoellman (2010). While Table 3 contains

\footnotetext{
${ }^{11}$ We used four sources to get education expenditures as a share of GDP, Tanzi and Schuknecht (2000), Lindert (2004), Digest of Education Statistics (2009) and various issues of the Human Development Report. For cohort schooling length we used Tamura, Devereux, Dwyer and Baier (2010), for enrollments and population we used B.R. Mitchell (2003) and Historical Statistics of the United States (2006).
} 
both a taste parameter, $\beta$, the crucial parameter for us is $\mu .^{12}$ The smaller the $\mu$ the more efficient a society is at transforming school time into human capital. Notice that there is a large cluster of countries at the US value of $\mu=.0850$. Only France and Norway have schooling efficiency better than the US. The countries with inferior schooling efficiency than the US are Belgium, Canada, Denmark, Germany, Greece, Japan, Netherlands, New Zealand, Portugal, Spain, Sweden, Switzerland and the UK. The countries that are comparable in efficiency are Australia, Austria, Finland, Ireland,and Italy.

\section{Conclusion and future work}

This paper has presented a model capable of capturing the secular decline in fertility of the United States and 20 other western countries. In addition it captures the significant Baby Booms that occurred in these countries. It is able to fit the dramatic increase in schooling for all of these countries over the last 200 years, and more importantly to capture the increase in schooling the occurred even during or in some countries accelerated during the Baby Boom. The model assumes that the secular decline in fertility that occurred in these countries is mainly driven by falling precautionary demand for children as young adult mortality declines. The model assumes that the price of space is the driving variable for the Baby Booms in these countries. One weakness in this model is that we must have an offsetting change in the price of schooling during the declining price of space in order to produce the observed rise in schooling. ${ }^{13}$ We consider the numerical solutions to be an exercise in quantitative identification. That is to say we force the model to fit the data by allowing the crucial variables to vary over time. Thus the model solutions provide economists with the time series of the price of space and cost of schooling that must have occurred in order to produce the observed phenomena. We provide limited evidence on the price of space and more comprehensive information on the cost of schooling. In both of these cases the evidence is supportive of the model.

In other work, we, along with Kevin M. Murphy, have produced new data for the states of the United States. We document in our joint paper (2008) that the states of the United States have the similar declines in fertility secularly, but differential magnitudes of Baby Booms. Using data from censuses of the US population, we produce time series of fertility, mortality risk from 1850 - 2000. We combine this data with data from Turner, Tamura, Mulholland and Baier (2007) on schooling at the state level over this period. Typically the states that had below the national average fertility, the New England, Middle Atlantic, East North Central West North Central, and Pacific census regions, had larger than average Baby Booms. The remaining states, the South Atlantic, East South Central, West South Central and Mountain census regions, had smaller than average Baby Booms. We also show that the states with larger than average Baby Booms had higher schooling at the start, but added fewer years of schooling over time, than their smaller than average Baby Boom counterparts. The states with larger than average Baby Booms

\footnotetext{
${ }^{12}$ In the precautionary demand for fertility term in preferences, the stationary value of $\nu$ differs from the baseline case of .400 in only three cases, France, Netherlands and New Zealand. There is more heterogeneity in preference parameter $\beta$. The possible values are .18 (nine countries), .27 (three countries), .30 (one country), .36 (two countries), .45 (one country), .54 (two countries), .63 (one country), .72 (one country) and .75 (one country). In the limit, the young adult mortality converges to 0 , and all of these differences vanish.

${ }^{13}$ Ideally it would have been preferred to have the price of space and the cost of schooling be relatively uncorrelated. However many school systems are tied to the property tax on housing. So at least in terms of the United States we would expect to see a correlation between the two. The dramatic decline in the price of space along with the decline in the cost of schooling suggest that the suburbanization mechanism must be studied in greater detail. For the model to be correct, it must be the case that along with the falling price of space, the newer suburban schools must have been of dramatically higher quality than the urban schools that existed before them.
} 
are also the states that had higher initial population density, and would have had the greatest reduction in the price of space arising from suburbanization. 


\section{References}

[1] Acemoglu, Daron, David Autor, and David Lyle, "Women, War and Wages: The Effect of Female Labor Supply on the Wage Structure at Midcentury," Journal of Political Economy 112, 2004: 497-551.

[2] Anas, Alex, Richard Arnott, and Kenneth A. Small. "Urban Spatial Structure," Journal of Economic Literature 36, 1998: 1426-64.

[3] Arroyo, Cristino R. and Junsen Zhang, "Dynamic Microeconomic Models of Fertility Choice: A Survey," Journal of Population Economics 10, 1997: 23-65.

[4] Baier, Scott, Gerald P. Dwyer, and Robert Tamura. "How Important Are Capital and Total Factor Productivity for Economic Growth?" Economic Inquiry 44, 2006: 23-49.

[5] Bailey, Martha J. and Collins, William J. "The Demographic Effects of Household Electrification in the United States, 1925 to 1960," Vanderbilt University working paper, 2006.

[6] Becker, Gary. "An economic analysis of fertility," in Demographic and Economic Change in Developed Countries, National Bureau of Economic Research Conference Series 11 NBER, Princeton, NJ. 1960: 209-31.

[7] Chatterjee, Satyajit and Gerald A. Carlino. "Aggregate Metropolitan Employment Growth and the Deconcentration of Metropolitan Employment," Journal of Monetary Economics 48, 2001: 549-83.

[8] Cuberes, David, and Robert Tamura. "The Gap Between Equilibrium and Optimal Fertility Under Declining Mortality," Clemson University working paper.

[9] Del Boca, Daniela, Silvia Pasqua, and Chiara Pronzato. "Employment and Fertility Decisions of European Women.” Working Paper 2004.

[10] Fernández, Racquel, Alessandra Fogli, and Claudia Olivetti, "Mothers and Sons: Preference Formation and Female Labor Force Dynamics," Quarterly Journal of Economcs 119, 2004: 1249-1300.

[11] Greene, William H. Econometric Analysis, 5th Edition. Upper Saddle River, NJ, Prentice Hall, 2003.

[12] Greenwood, Jeremy, Ananth Seshadri, and Guillaume Vandenbroucke. "The Baby Boom and Baby Bust: Some Macroeconomics for Population Economics," American Economic Review, 95, 2005: 183-207.

[13] Guryan, Jonathan. "Desegration and Black Dropout Rates," American Economic Review 94, 2004: 919-43.

[14] Haurin, Donald R. and David Brasington. "School Quality and Real Housing Prices: Inter and Intra-Metropolitan Effects," Journal of Housing Economics 5, 1996: 351-68. 
[15] Hotz, V. Joseph, Jacob Alex Klerman, and Robert J. Willis. "The Economics of Fertility in Developed Countries," in Handbook of Population and Family Economics, edited by M.R. Rosenzweig and O. Stark. Amsterdam, Netherlands: Elsevier, 1997.

[16] Jones, Charles I. "Was an Industrial Revolution Inevitable? Economic Growth Over the Very Long Run" Advances in Macroeconomics 2, 2001: Article 1.

[17] Kim, Sukkoo and Robert A. Margo. "Historical Perspectives on U.S. Economic Geography." Working Paper 2003.

[18] Kalemli-Ozcan, Sebnem. "Does Mortality Decline Promote Economic Growth?" Journal of Economic Growth 7, 2002: 411-439.

[19] Kalemli-Ozcan, Sebnem. "A Stochastic Model of Mortality, Fertility and Human Capital Investment," Journal of Development Economics 62, 2003: 103-118.

[20] Murphy, Kevin M., Simon, Curtis, and Tamura, Robert. "Fertility Decline, Baby Boom and Economic Growth," Journal of Human Capital 2, 2008: 262-302.

[21] Naz, Ghazala, Øivind Anti Nilson, and Steinar Vagstand. "Education and Completed Fertility in Norway." Working Paper 2002.

[22] Nix, Robert. " $20^{\text {th }}$ Century Trends in Durable Good Consumption in the United States," unpublished M.A. thesis, Clemson University, 2004.

[23] Santos Silva, J.M.C. and Francisco Covas. "A modified hurdle model for completed fertility," Journal of Population Economics 13, 2000: 173-88.

[24] Sato, Yasuhiro. "Fertility and Economic Geography," in Handbook of Regional and Urban Economics, vol. 3, 2003.

[25] Schoellman, Todd. "The Causes and Consequences of Cross-Country Differences in Schooling Attainment," Clemson University working paper 2010.

[26] Simon, Curtis, Robert Tamura. "Do Higher Rents Discourage Fertility? Evidence from U.S. Cities, 1940-2000," forthcoming Regional Science 63 Urban Economics 2008..

[27] Tamura, Robert. "Income Convergence in an Endogenous Growth Model," Journal of Political Economy 99, 1991: 522-540.

[28] Tamura, Robert. "From Decay to Growth: A Demogrphic Transition to Economic Growth," Journal of Economic Dynamics and Control 20, 1996: 1237-1261.

[29] Tamura, Robert. "Human Capital and the Switch from Agriculture to Industry," Journal of Economic Dynamics and Control 27, 2002: 207-242.

[30] Tamura, Robert. "Human Capital and Economic Development," Journal of Development Economics 79, 2006: 26-72.

[31] Tamura, Robert, Devereux, John, Dwyer, Gerald P., Baier, Scott. "Growth over the Long Run," Clemson University working paper, 2009. 
[32] Turner, Chad, Robert Tamura, Sean Mulholland and Scott Baier. "Education and Income of the States of the United States: 1840 - 2000," Journal of Economic Growth 12, 2007: 101-158. 

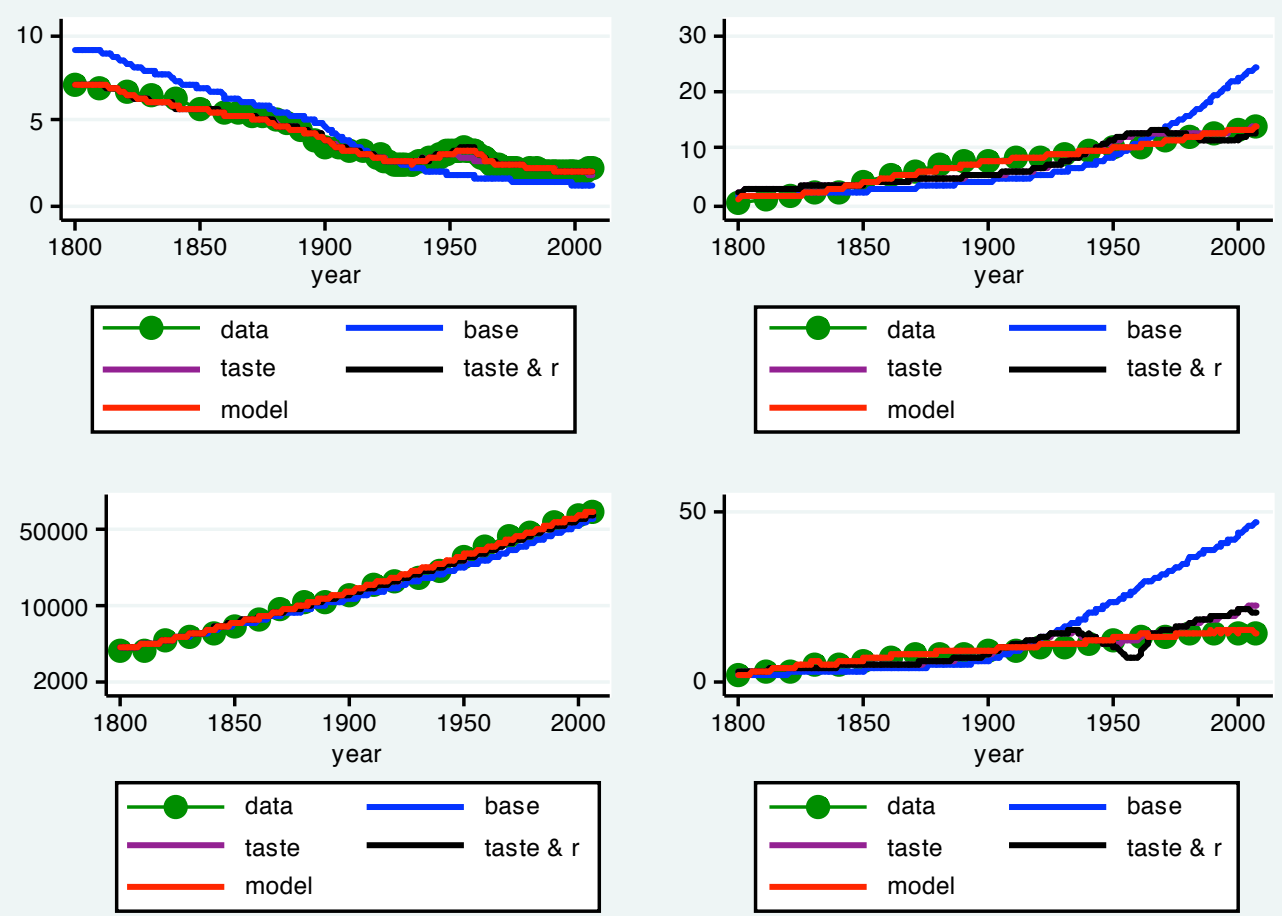

Figure 1: Fertility, Schooling, Real Output Per Worker, Young Schooling (clockwise): USA
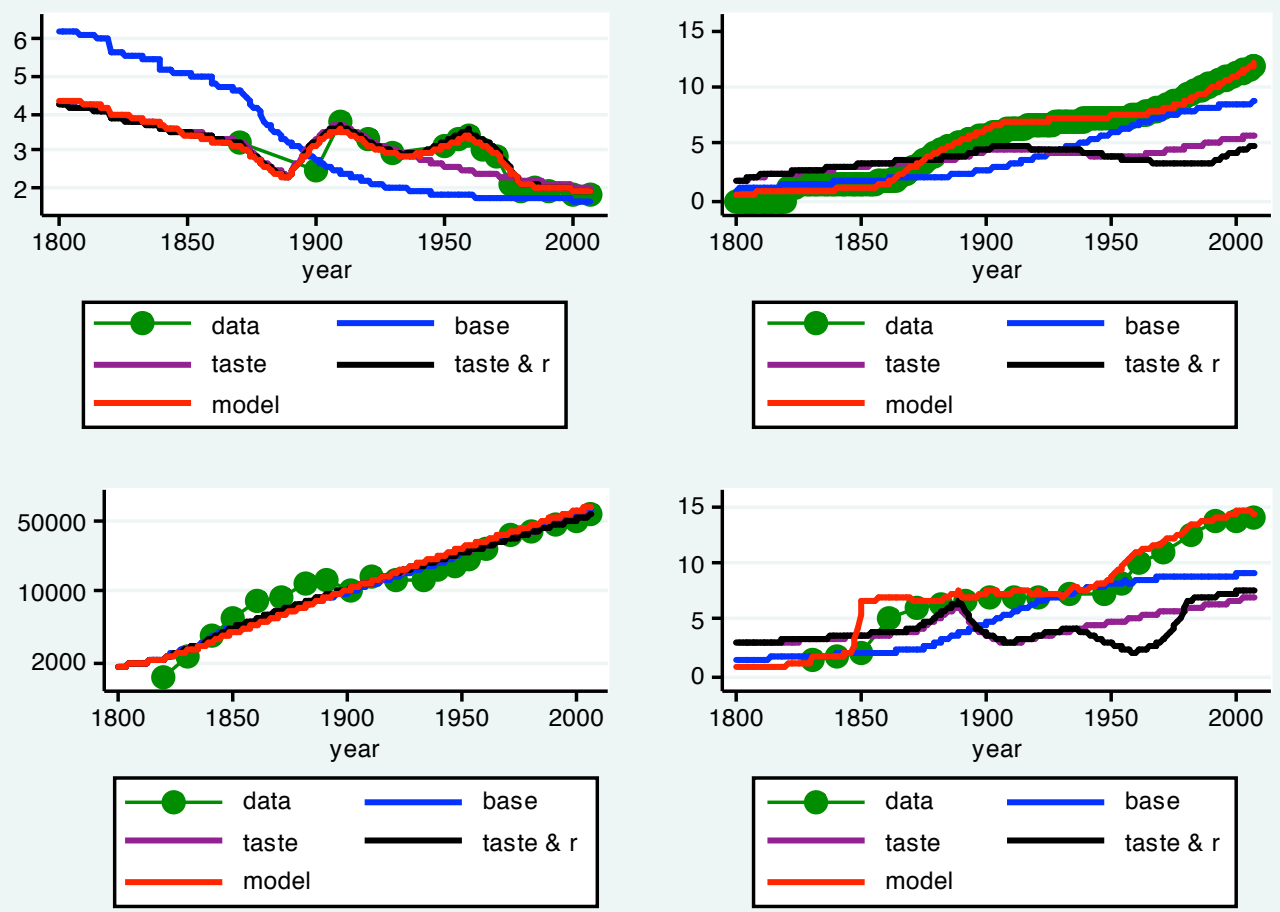

Figure 2: Fertility, Schooling, Real Output Per Worker, Young Schooling (clockwise): Australia 

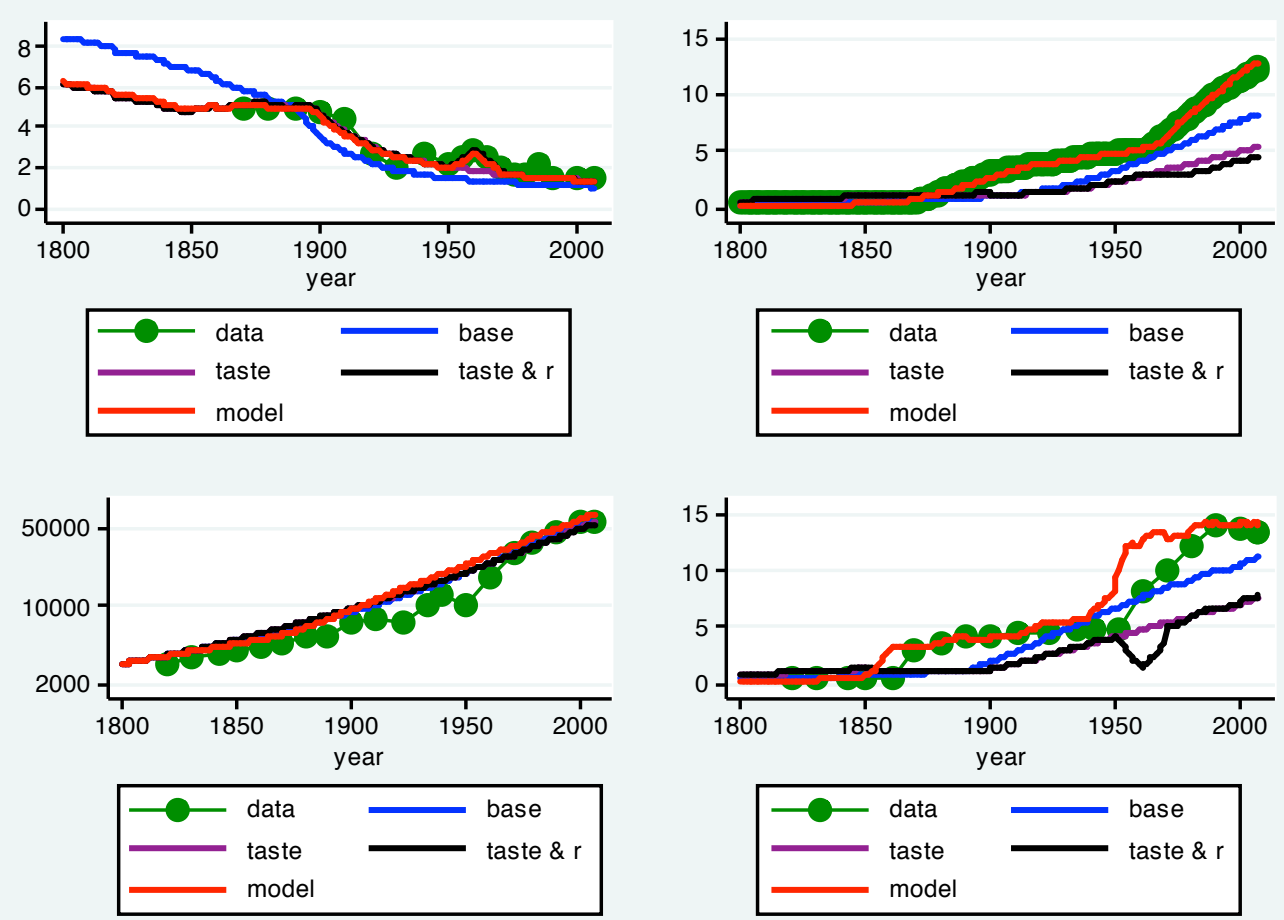

Figure 3: Fertility, Schooling, Real Output Per Worker, Young Schooling (clockwise): Austria
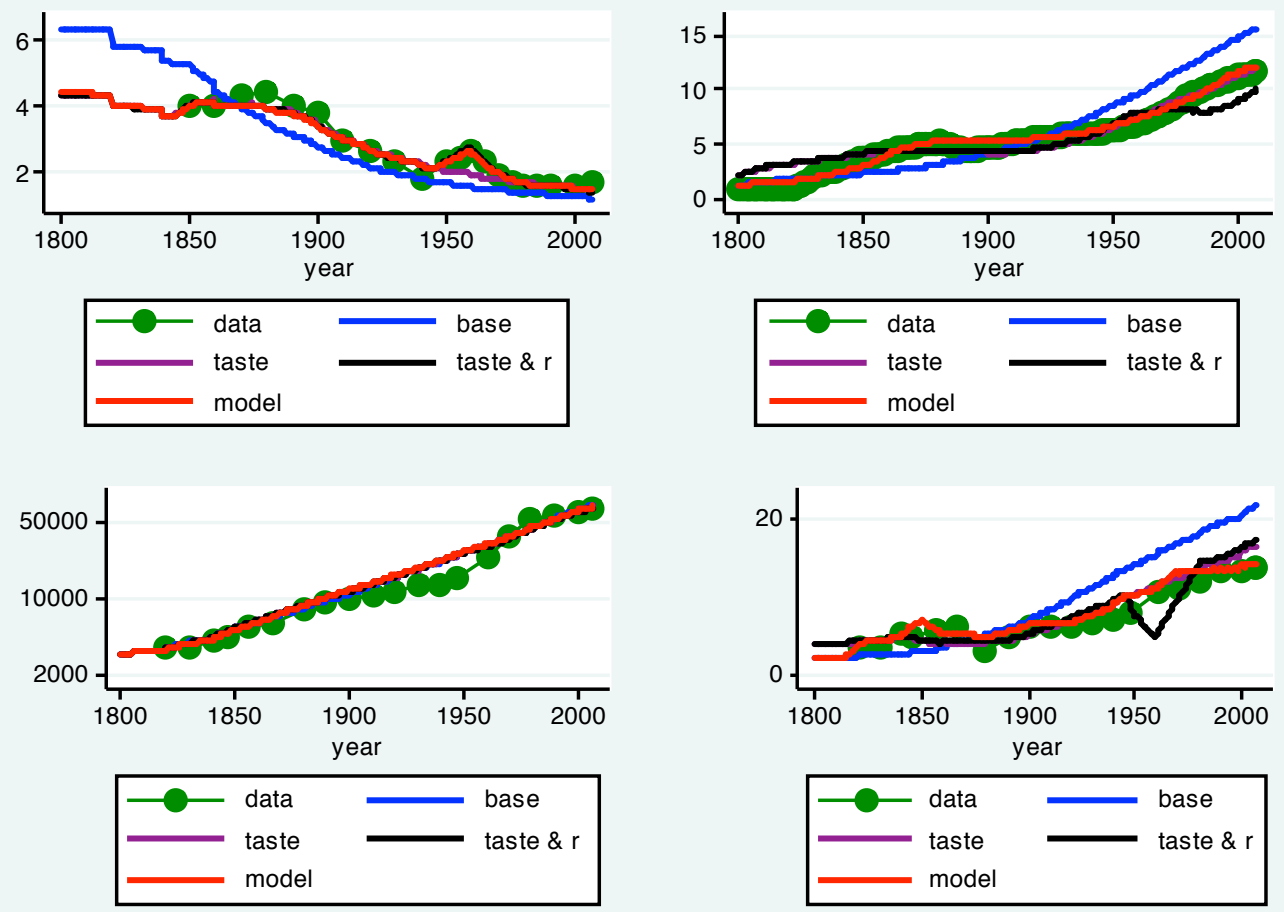

Figure 4: Fertility, Schooling, Real Output Per Worker, Young Schooling (clockwise): Belgium 

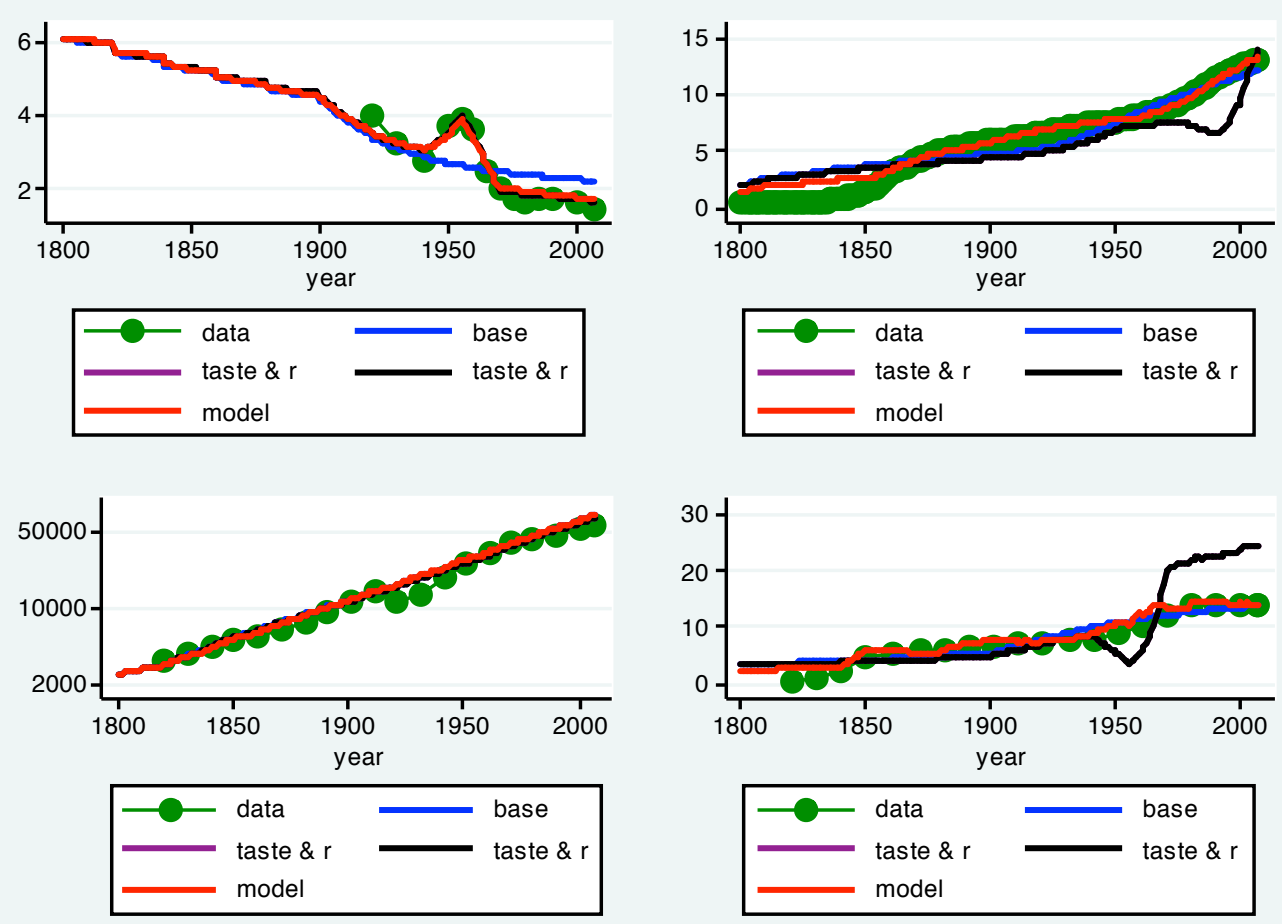

Figure 5: Fertility, Schooling, Real Output Per Worker, Young Schooling (clockwise): Canada
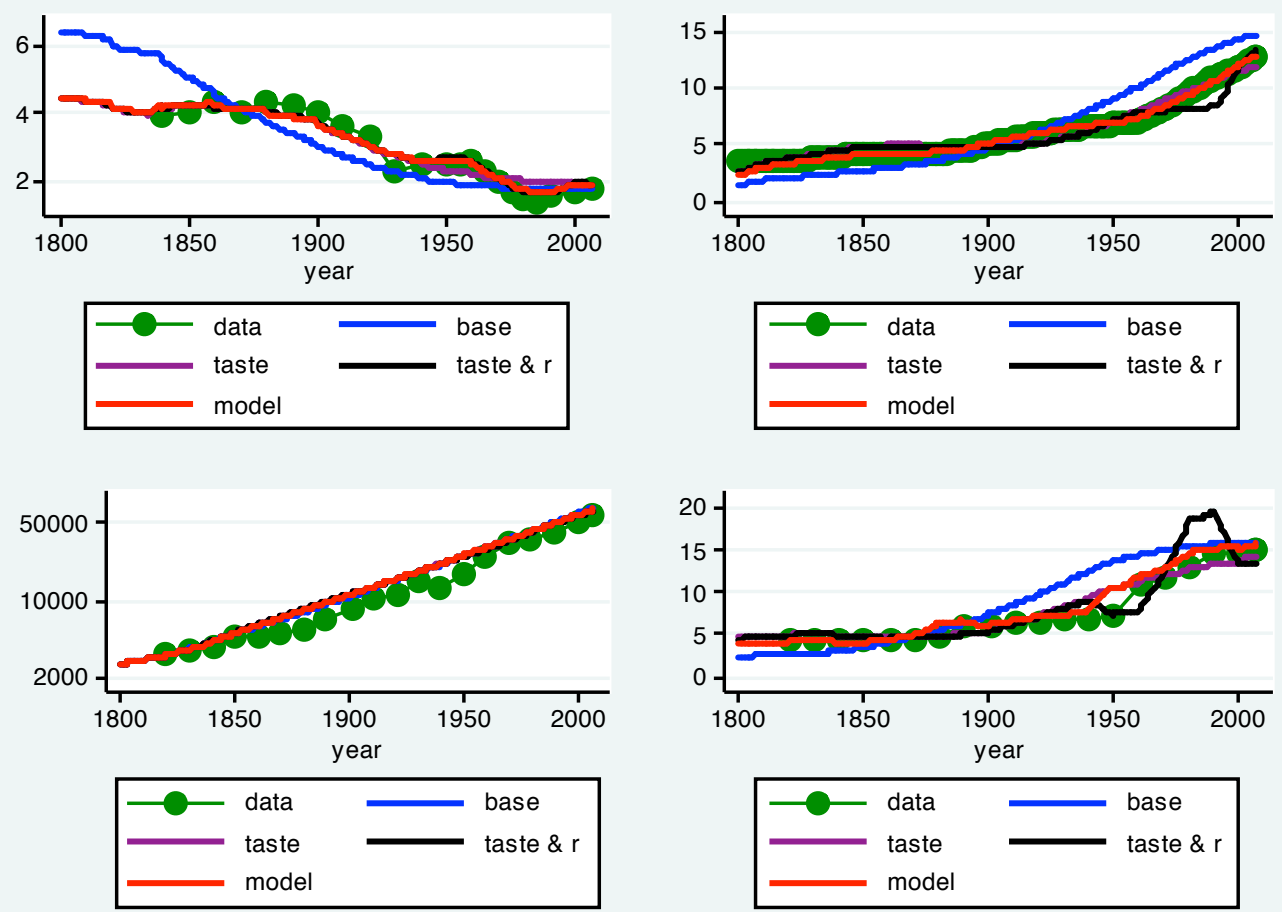

Figure 6: Fertility, Schooling, Real Output Per Worker, Young Schooling (clockwise): Denmark 

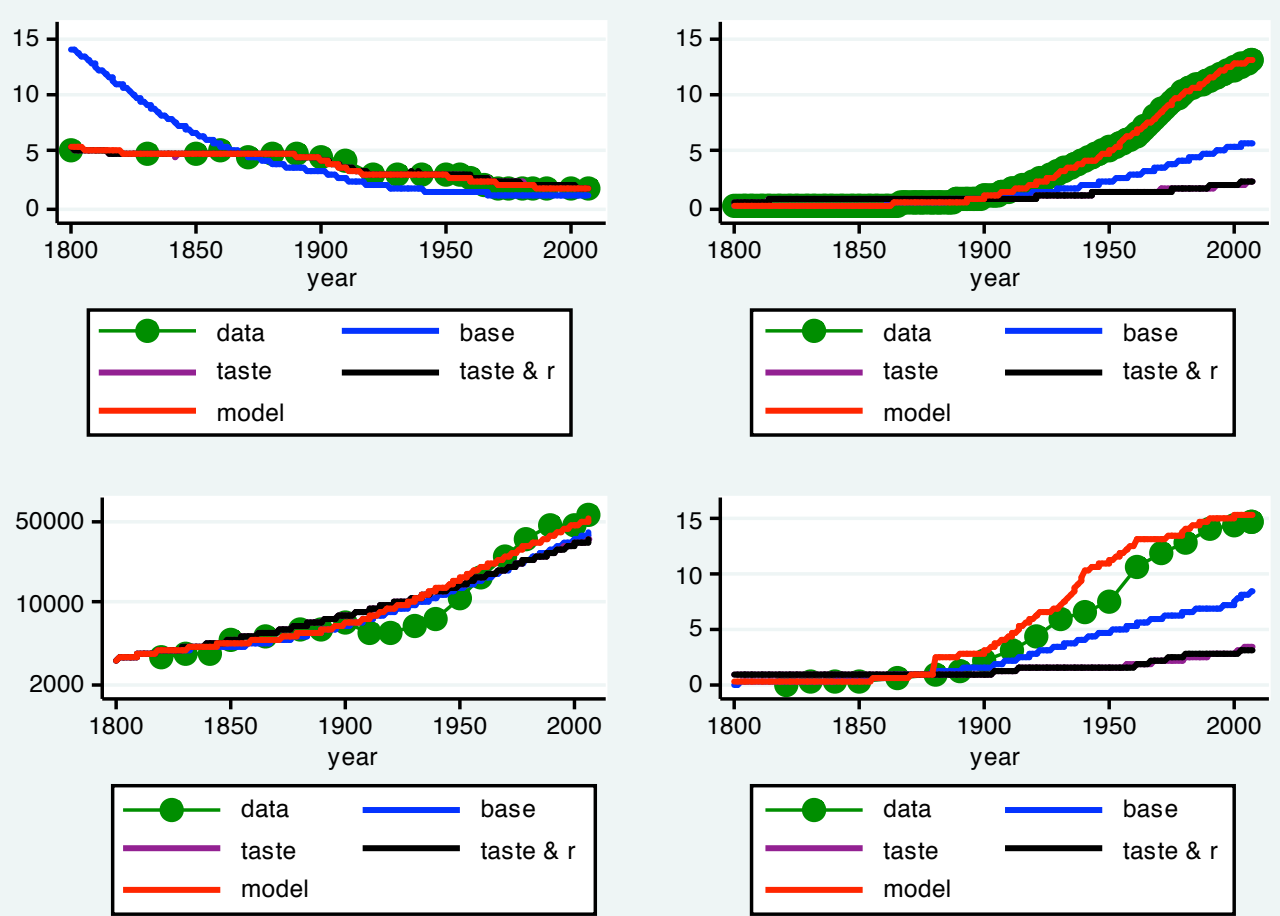

Figure 7: Fertility, Schooling, Real Output Per Worker, Young Schooling (clockwise): Finland
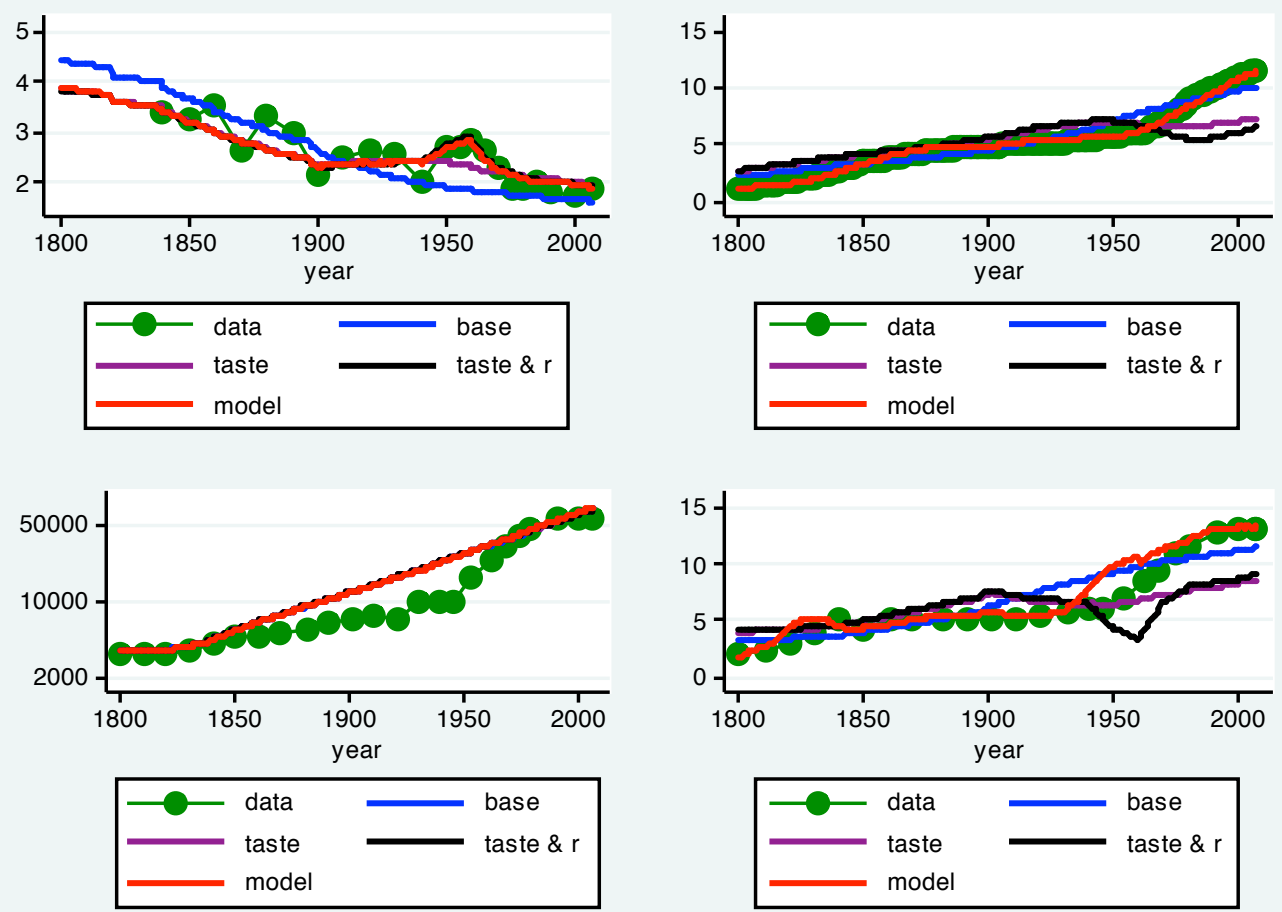

Figure 8: Fertility, Schooling, Real Output Per Worker, Young Schooling (clockwise): France 

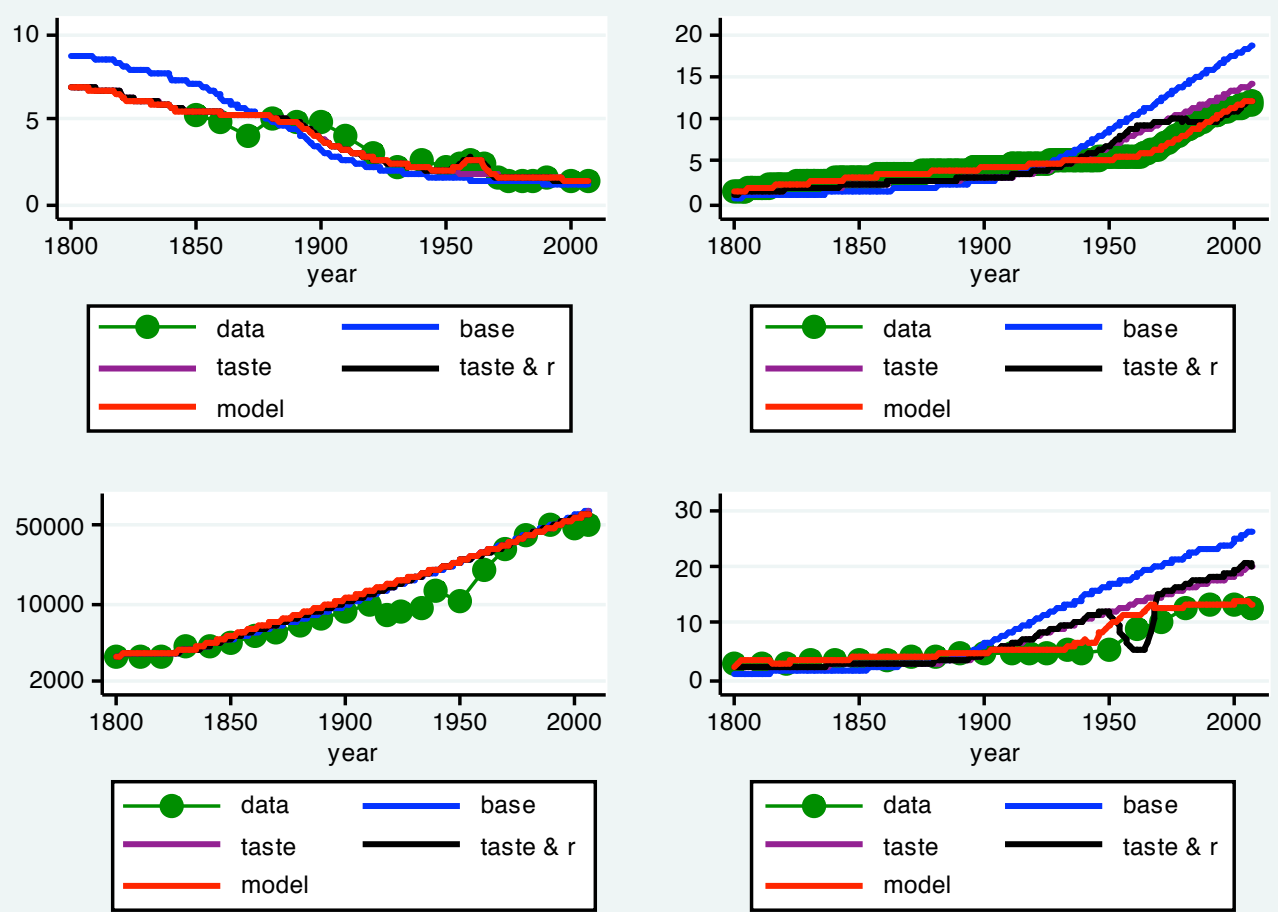

Figure 9: Fertility, Schooling, Real Output Per Worker, Young Schooling (clockwise): Germany
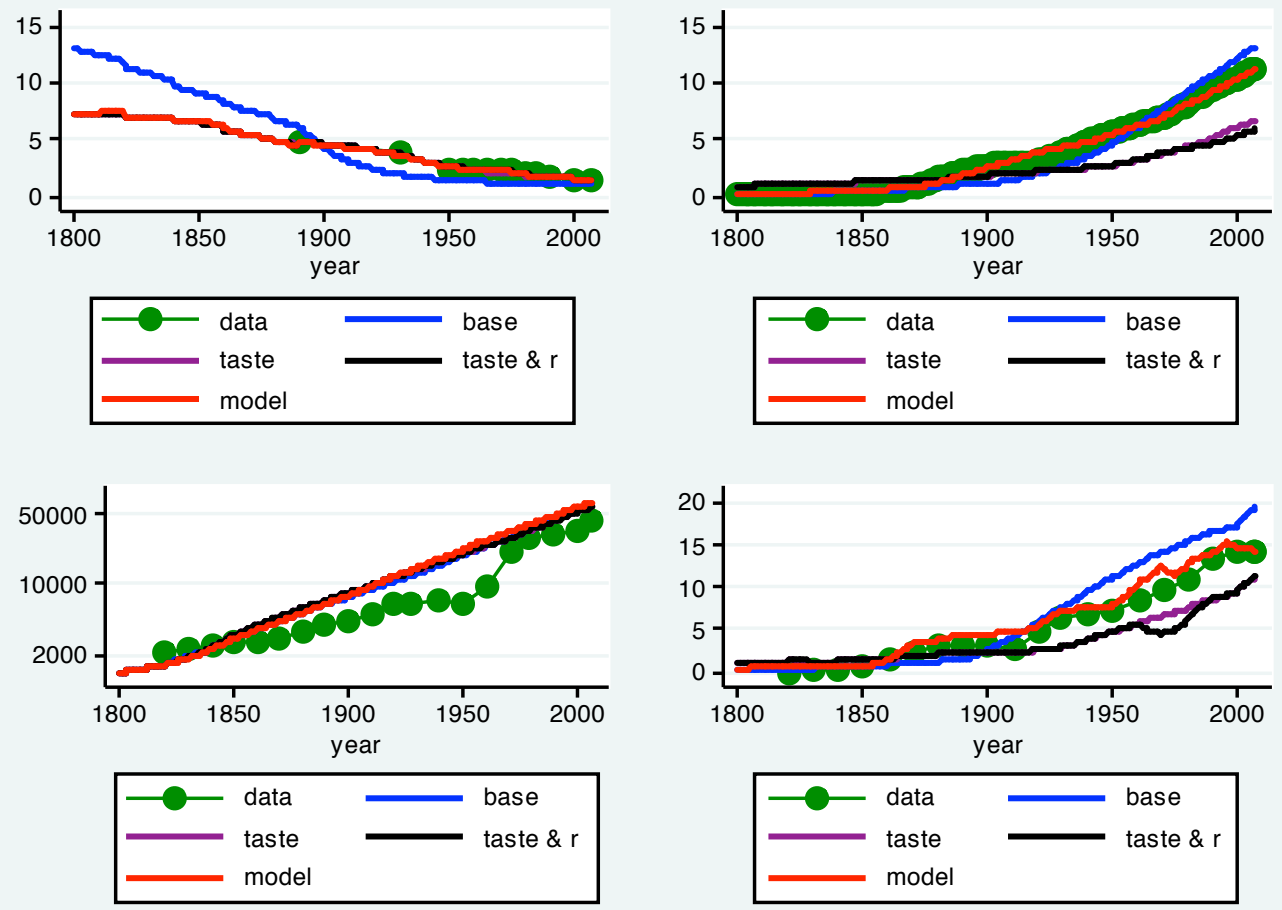

Figure 10: Fertility, Schooling, Real Output Per Worker, Young Schooling (clockwise): Greece 

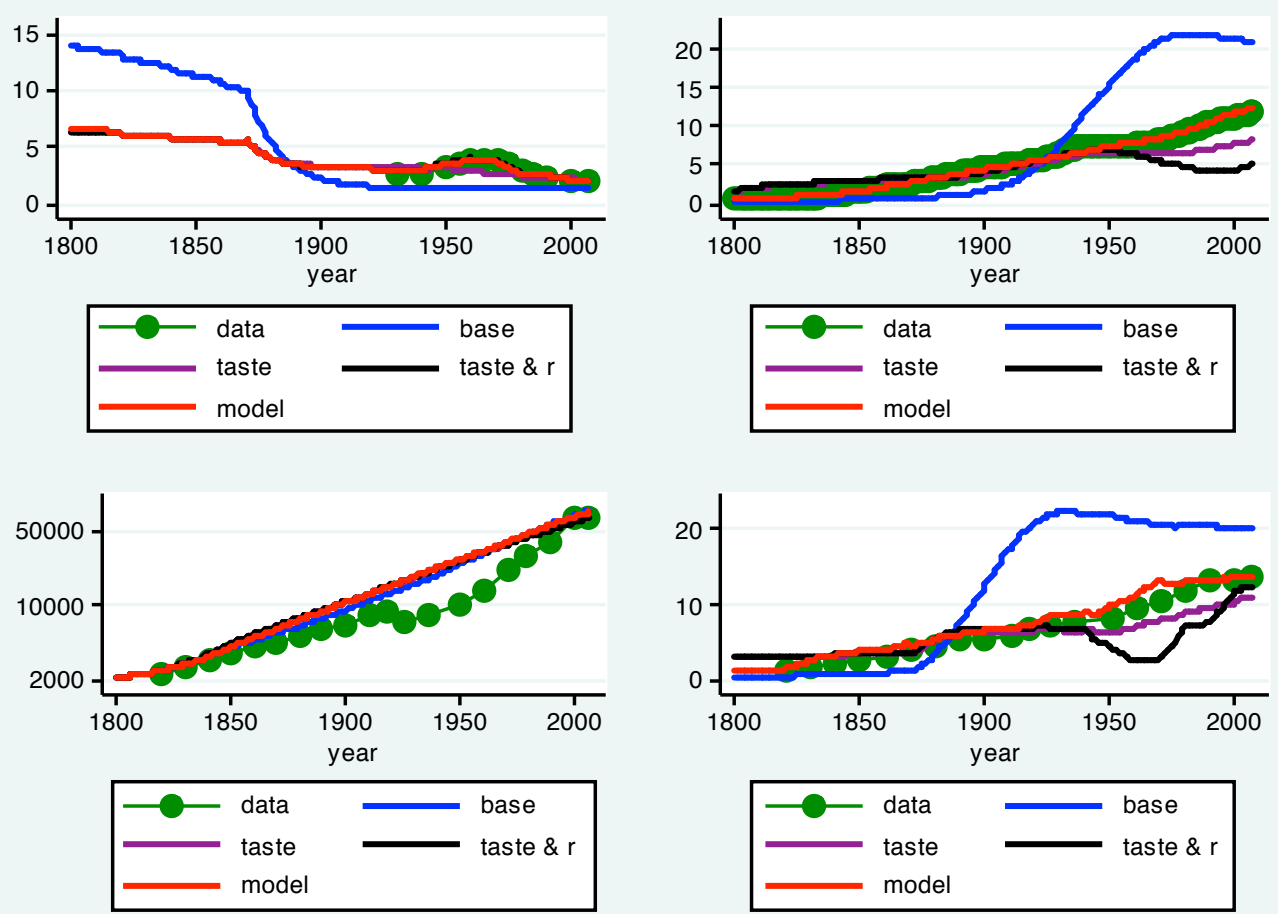

Figure 11: Fertility, Schooling, Real Output Per Worker, Young Schooling (clockwise): Ireland
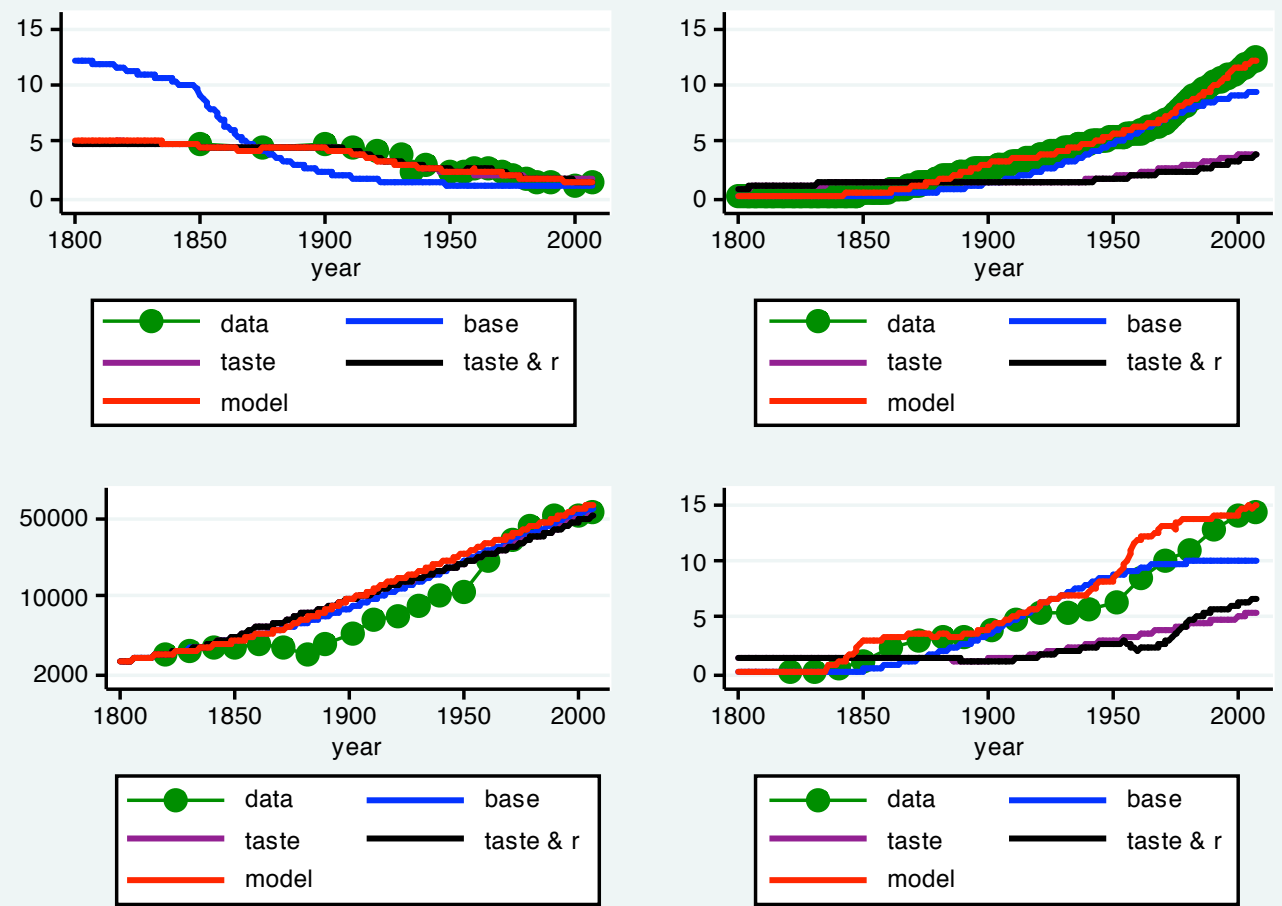

Figure 12: Fertility, Schooling, Real Output Per Worker, Young Schooling (clockwise): Italy 

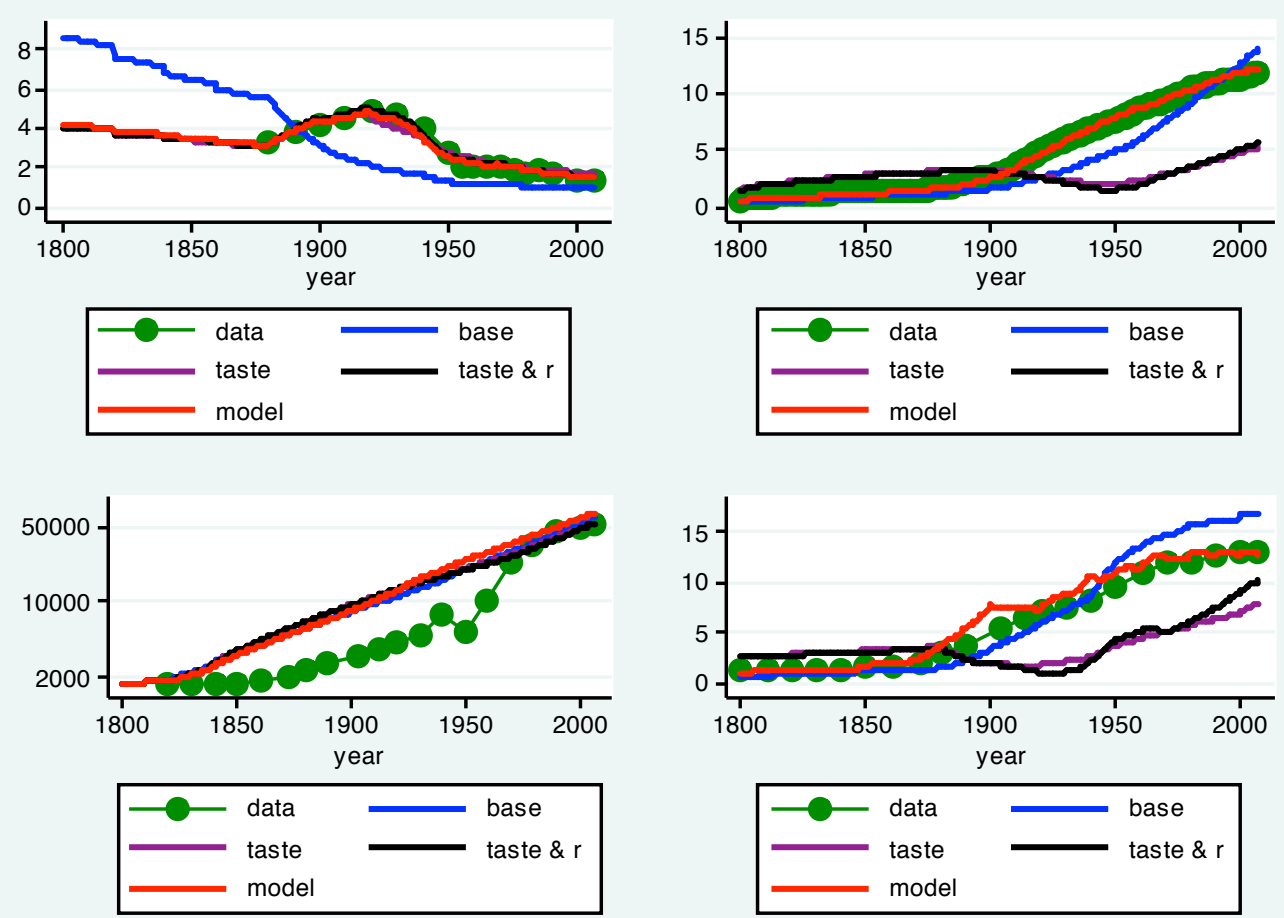

Figure 13: Fertility, Schooling, Real Output Per Worker, Young Schooling (clockwise): Japan
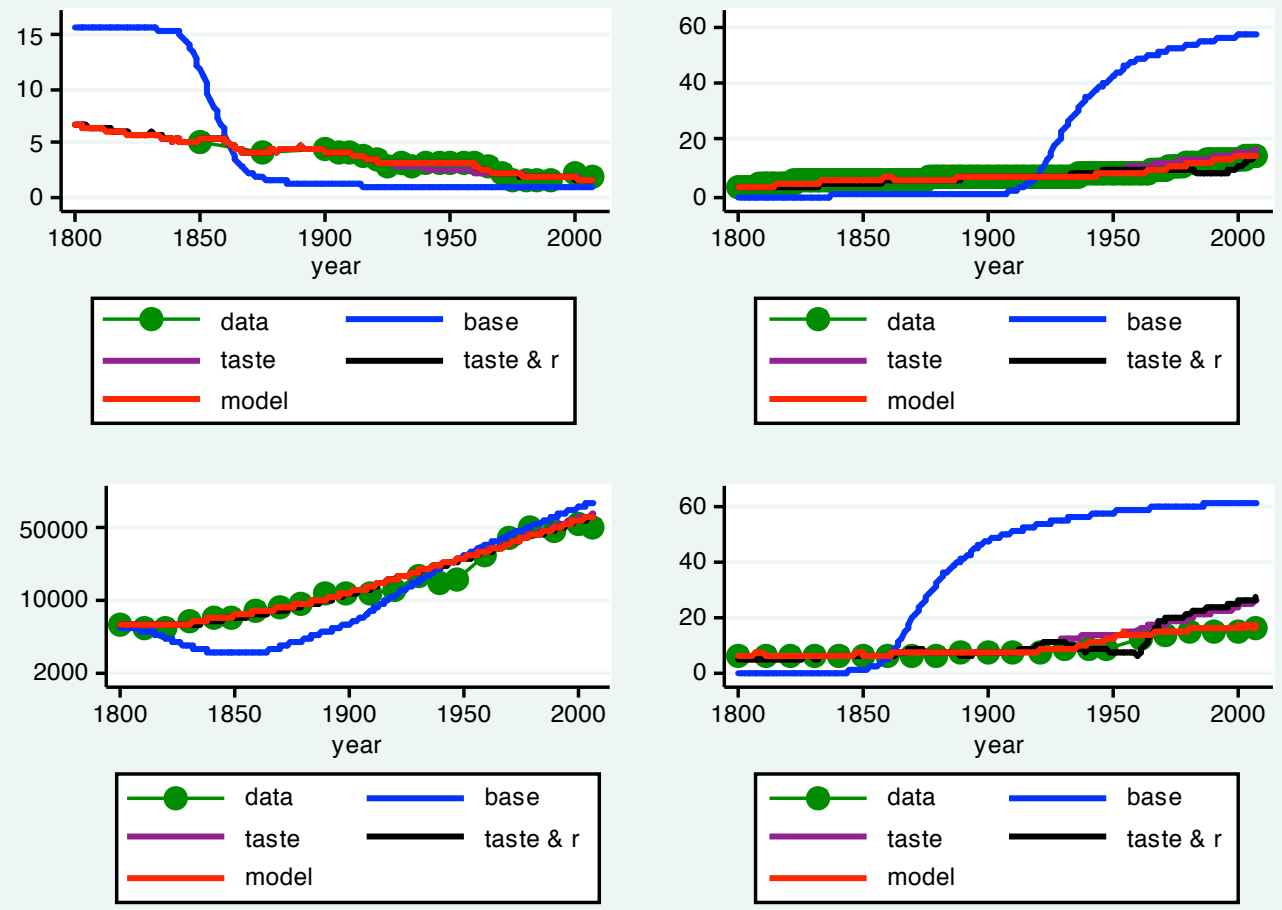

Figure 14: Fertility, Schooling, Real Output Per Worker, Young Schooling (clockwise): Netherlands 

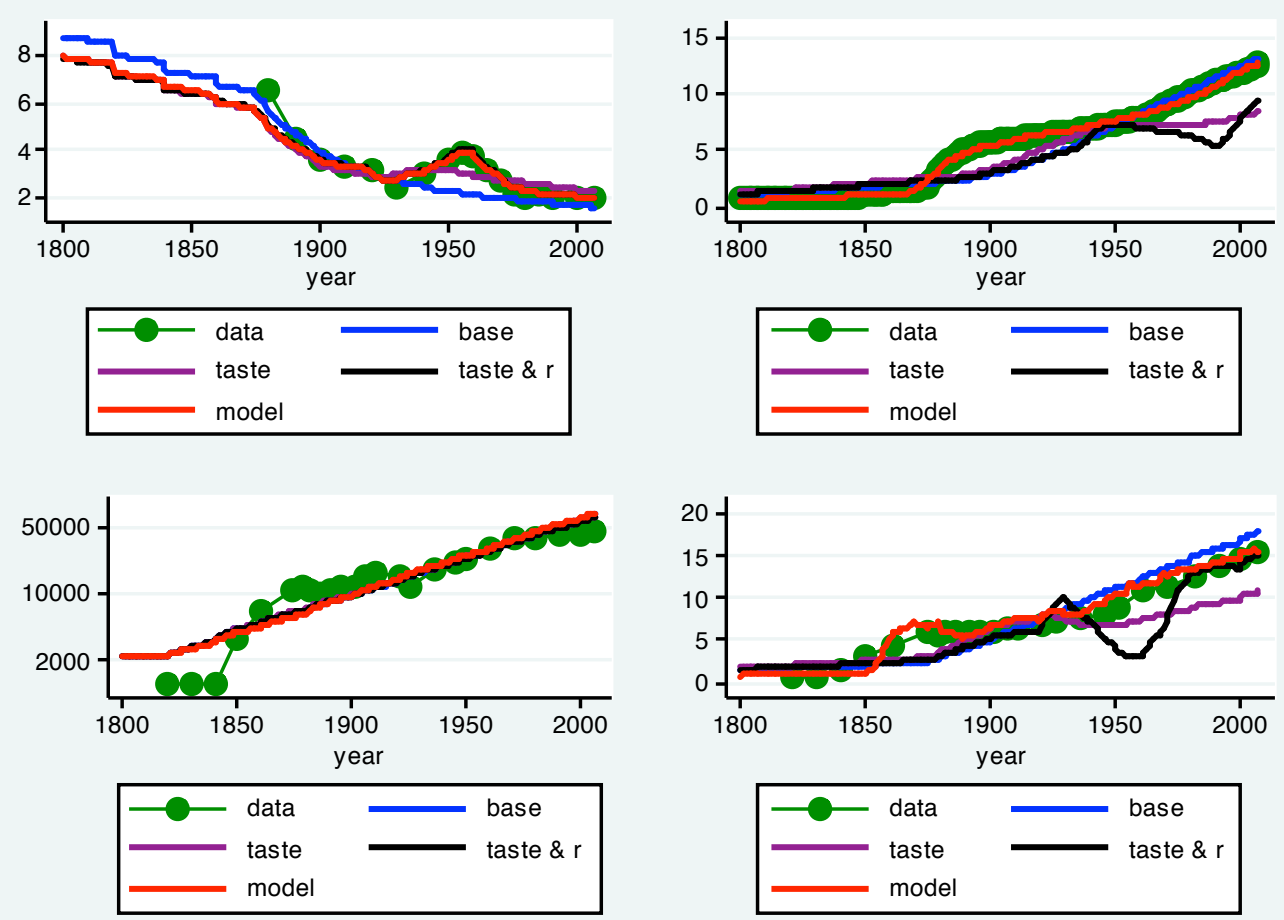

Figure 15: Fertility, Schooling, Real Output Per Worker, Young Schooling (clockwise): New Zealand
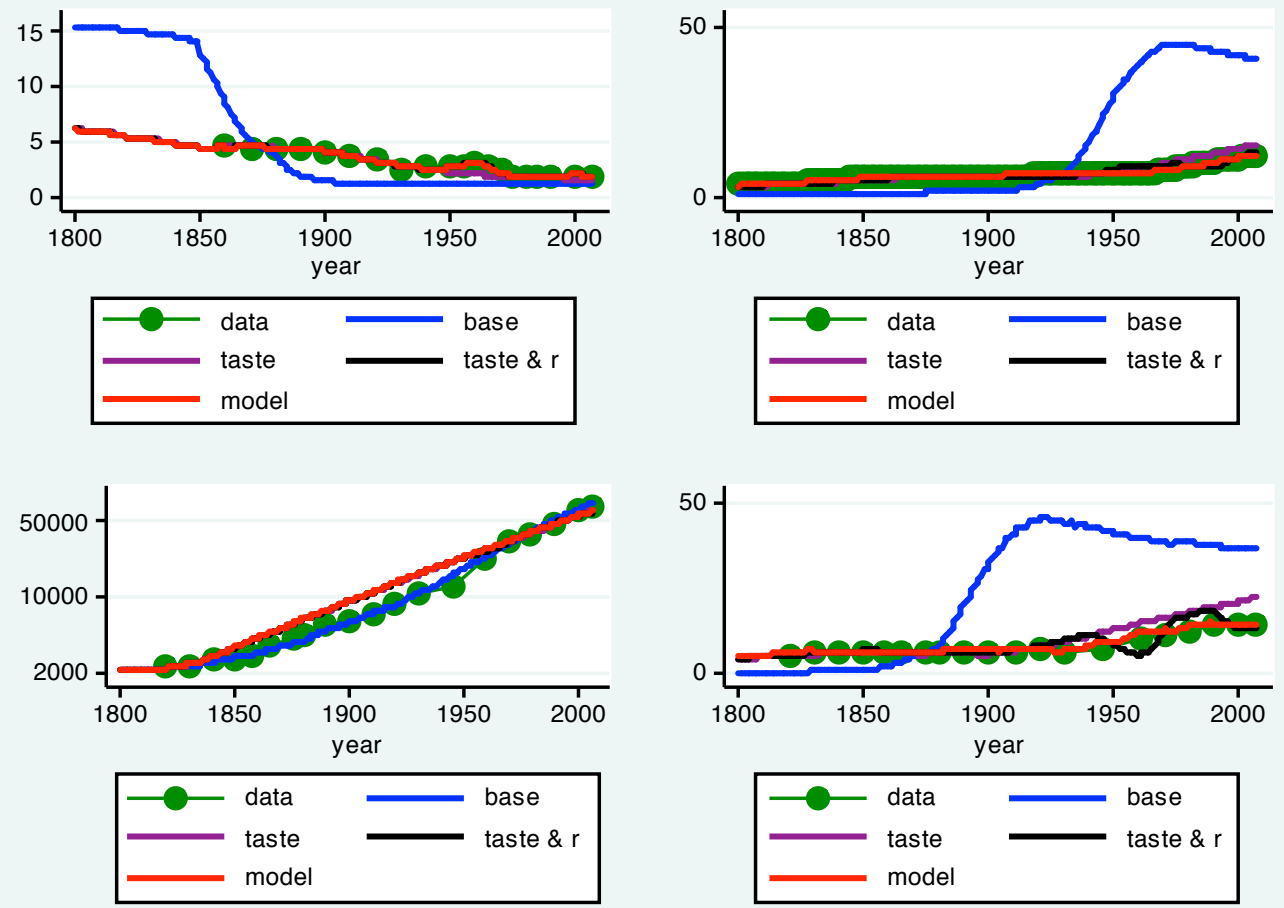

Figure 16: Fertility, Schooling, Real Output Per Worker, Young Schooling (clockwise): Norway 

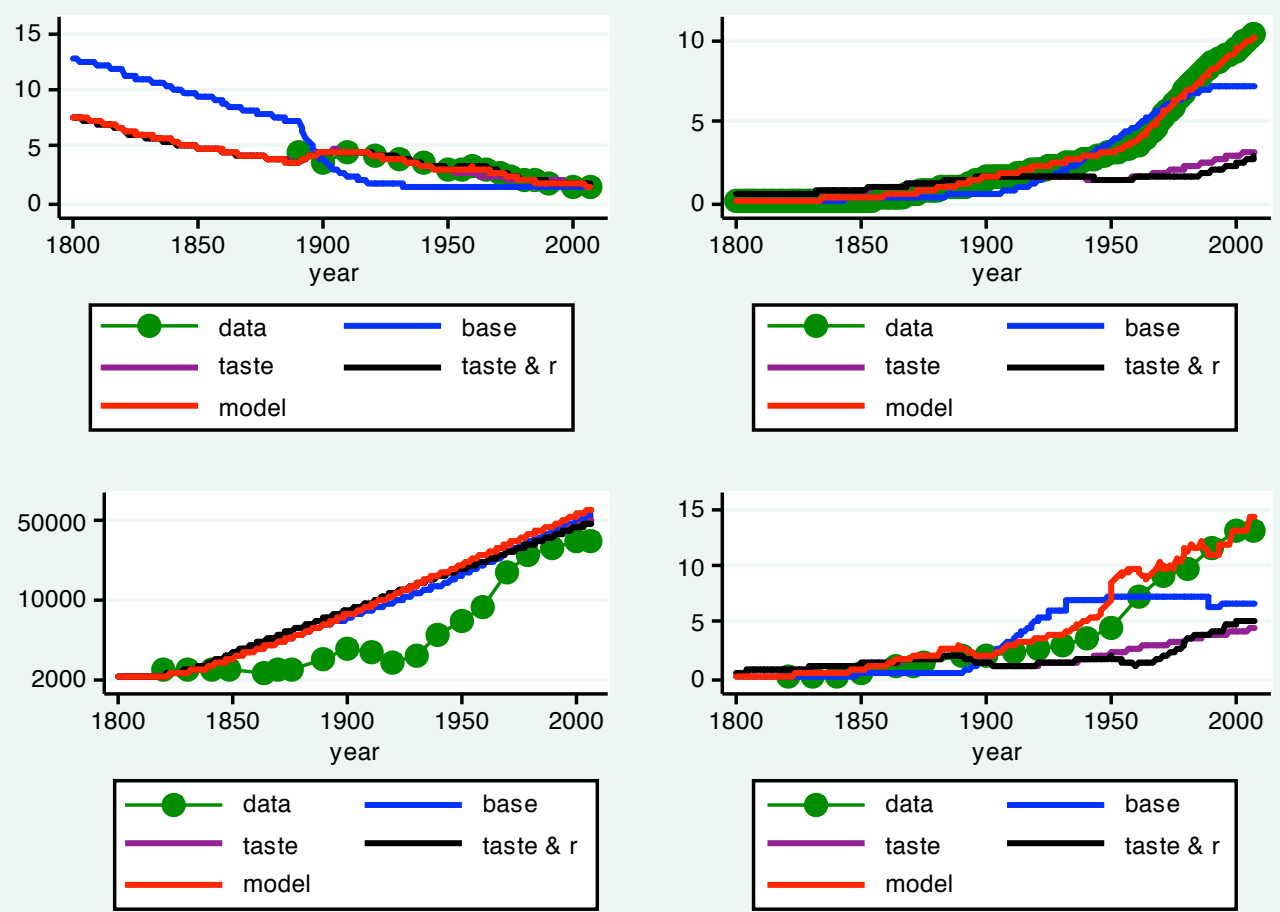

Figure 17: Fertility, Schooling, Real Output Per Worker, Young Schooling (clockwise): Portugal
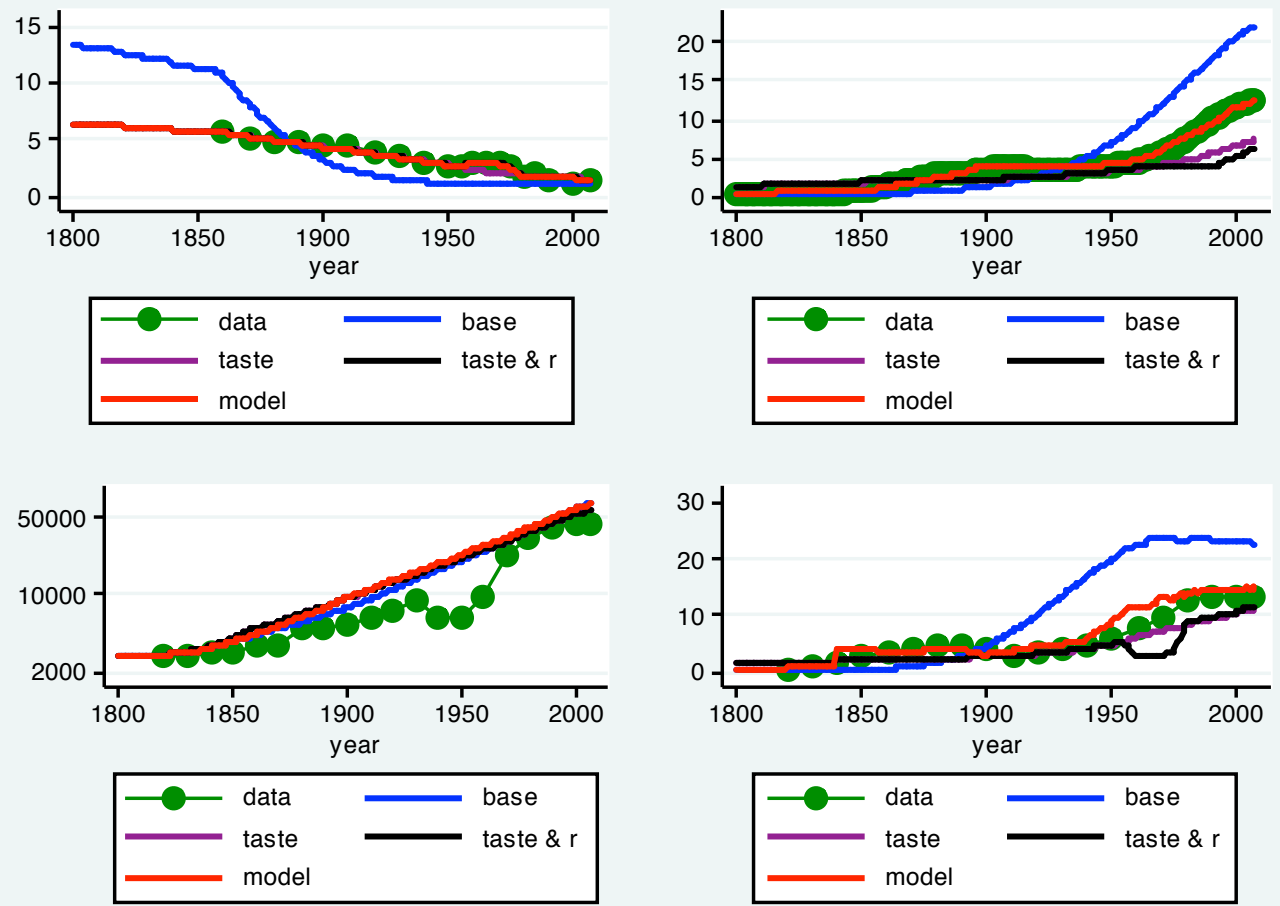

Figure 18: Fertility, Schooling, Real Output Per Worker, Young Schooling (clockwise): Spain 

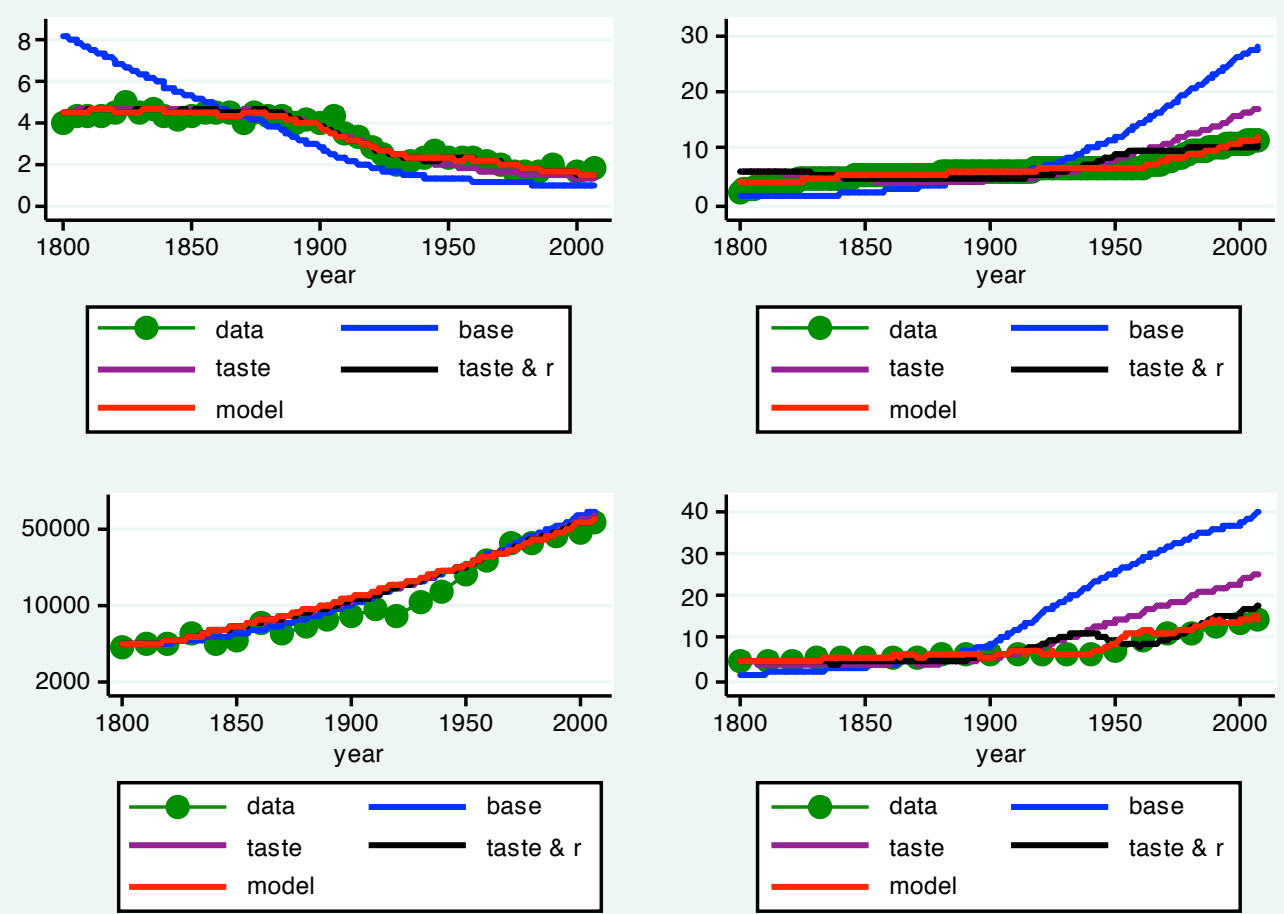

Figure 19: Fertility, Schooling, Real Output Per Worker, Young Schooling (clockwise): Sweden
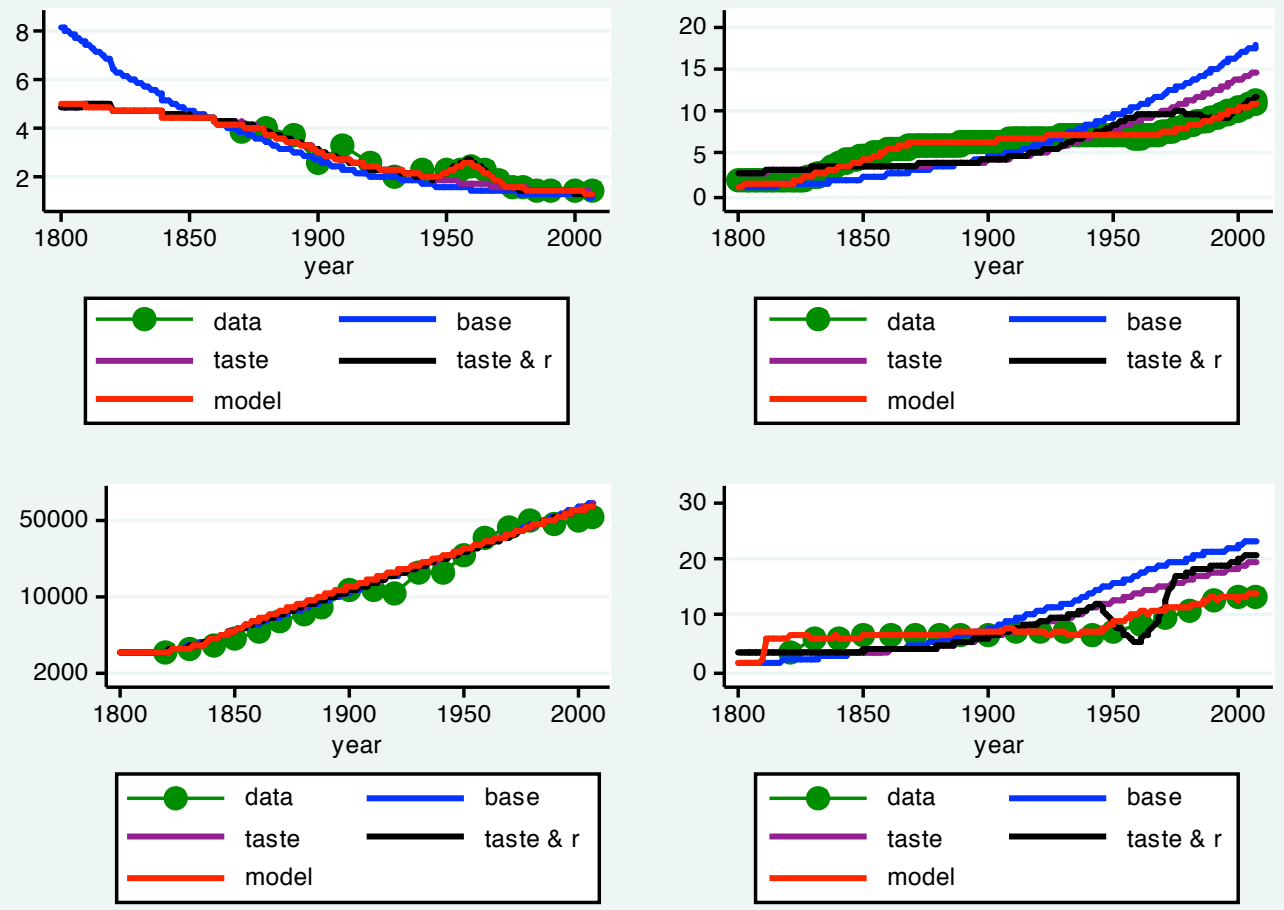

Figure 20: Fertility, Schooling, Real Output Per Worker, Young Schooling (clockwise): Switzerland 

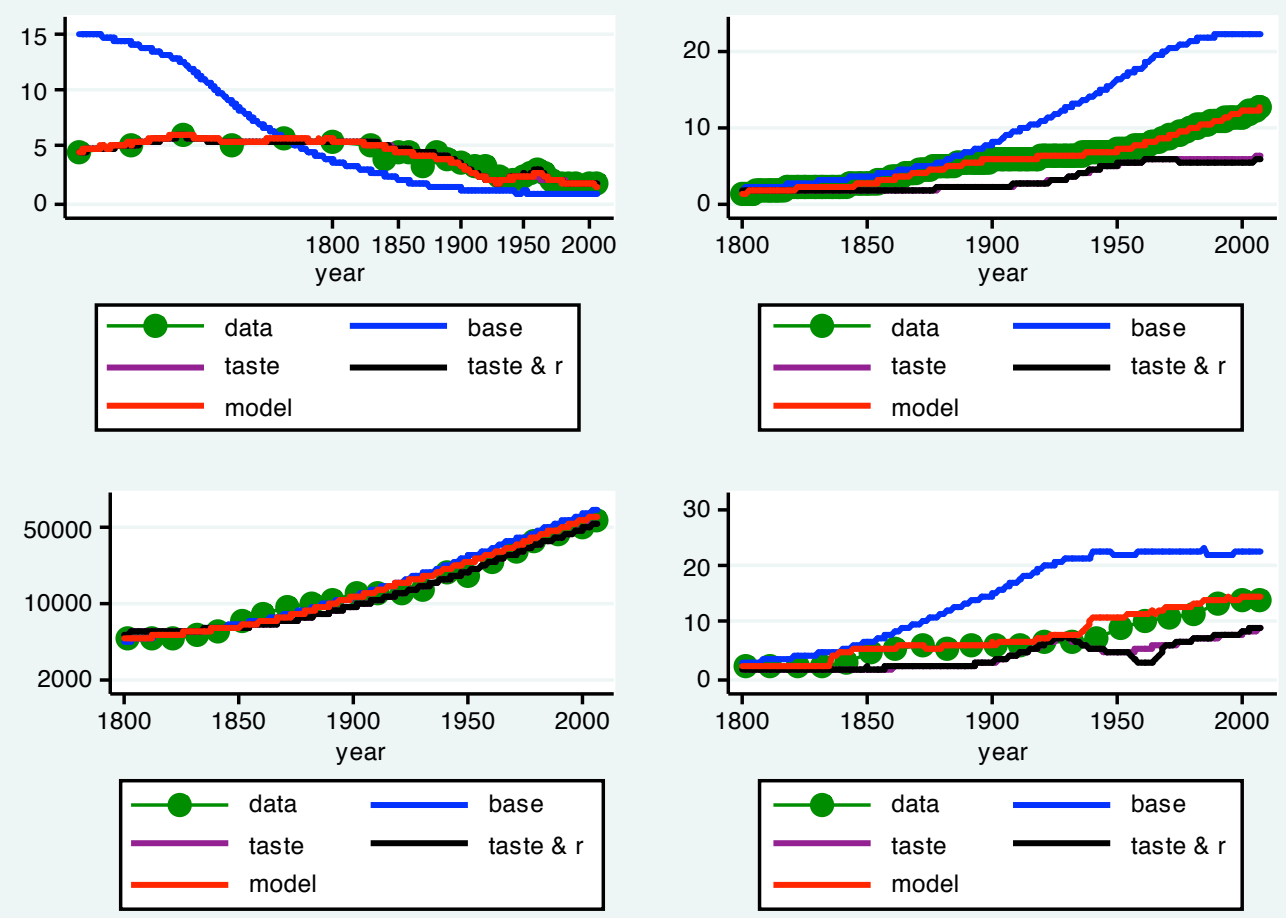

Figure 21: Fertility, Schooling, Real Output Per Worker, Young Schooling (clockwise): United Kingdom

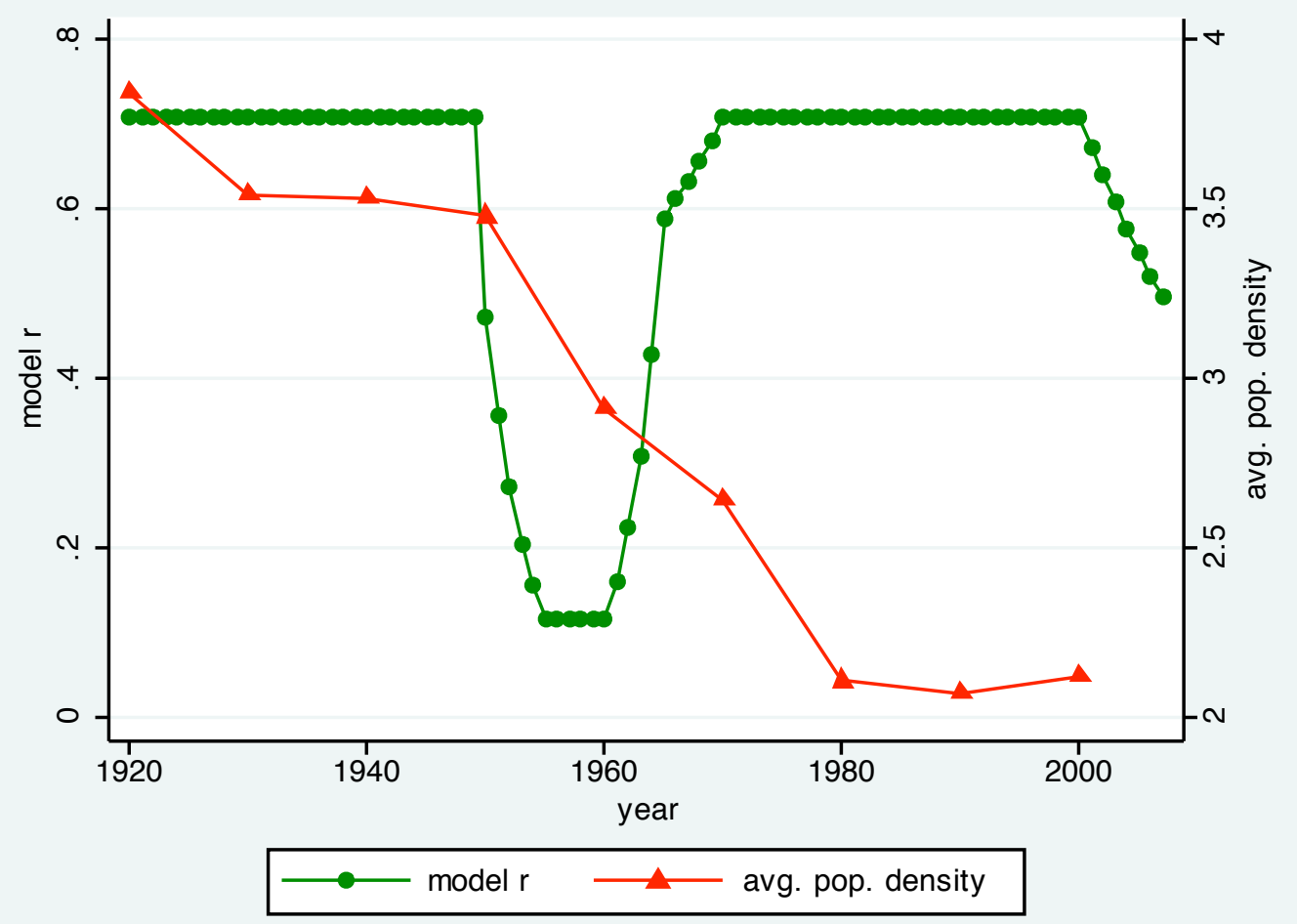

Figure 22: Model Rental Price of Space and US Population Density 

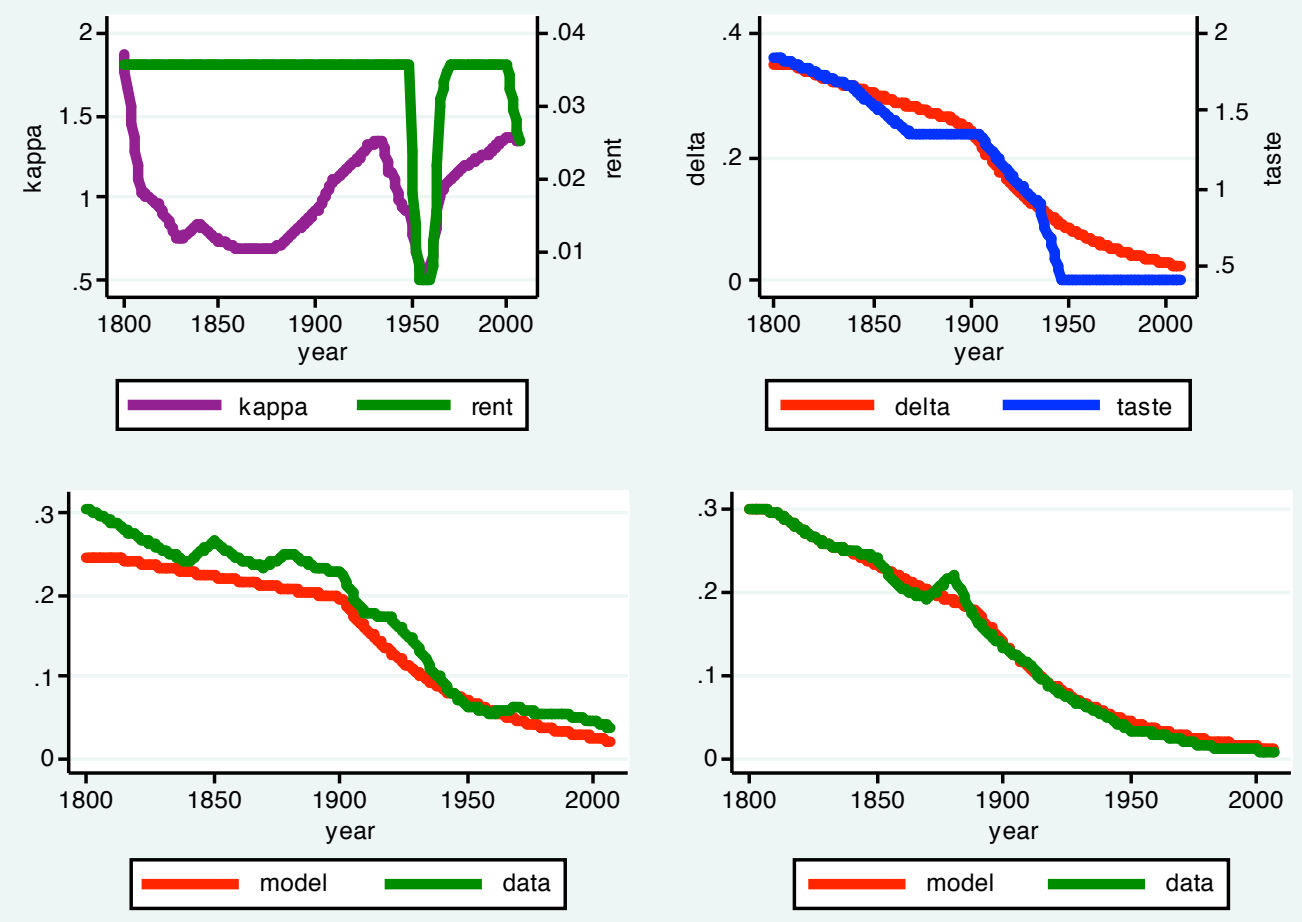

Figure 23: Rents, kappa, Taste Parameter $m u$ and Mortality: USA

\section{Appendix A: Rents, kappa, Taste Parameter and Mortality}

In this section we present the data for rents, $r$, preference parameter $\nu$, the cost of schooling per child, $\kappa$ and mortality. We present both the model mortality, based on splined regressions, both for mortality between the ages of 1 and 35, and infant mortality as well as the data for motality. In the splined regressions we split the data into two regimes, pre 1900 and 1900-1950. We shut off mortality from 1950 onward in the projections in order to capture the idea that the mass introduction of penicillin 

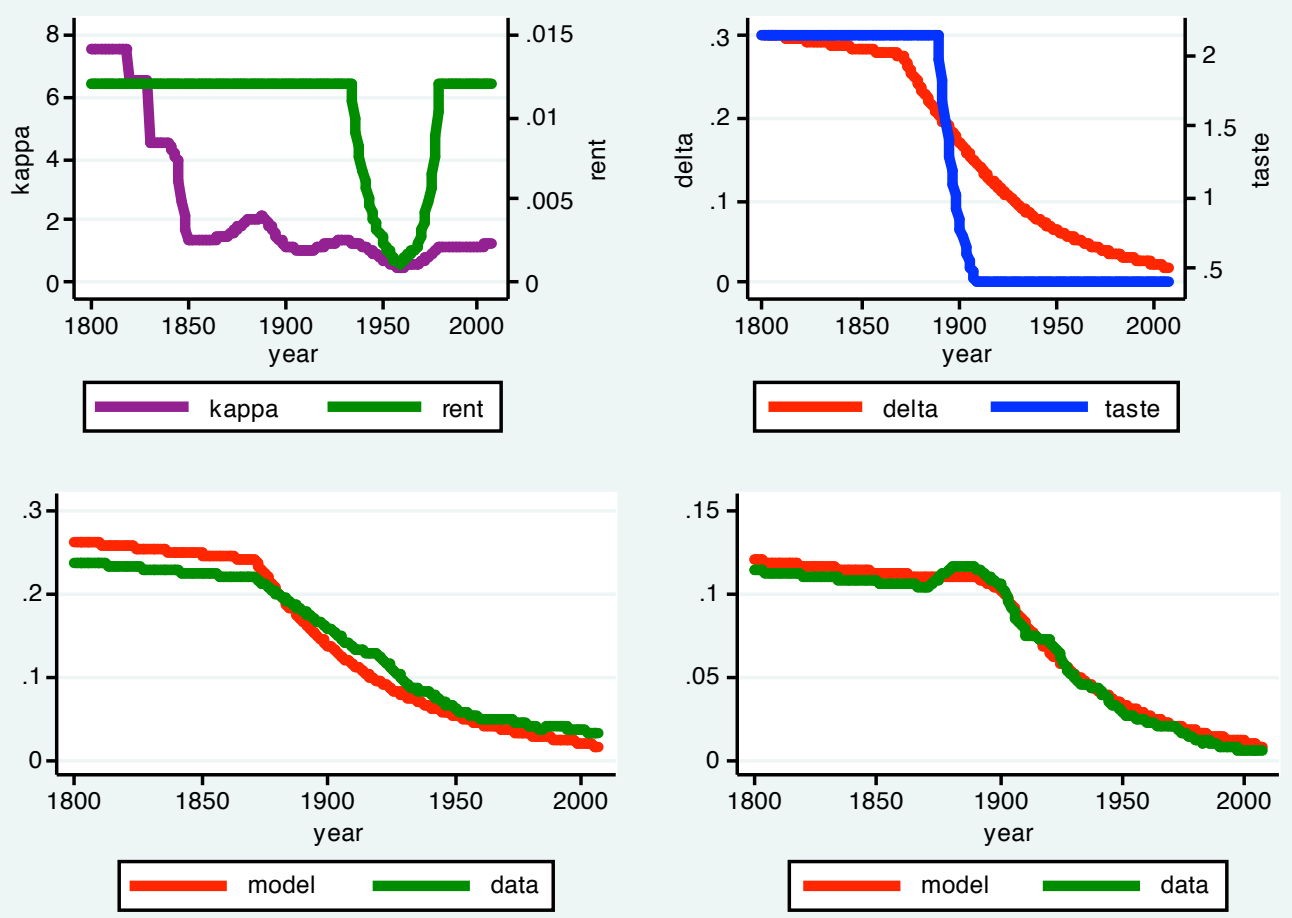

Figure 24: Rents, kappa, Taste Parameter mu and Mortality: : Australia
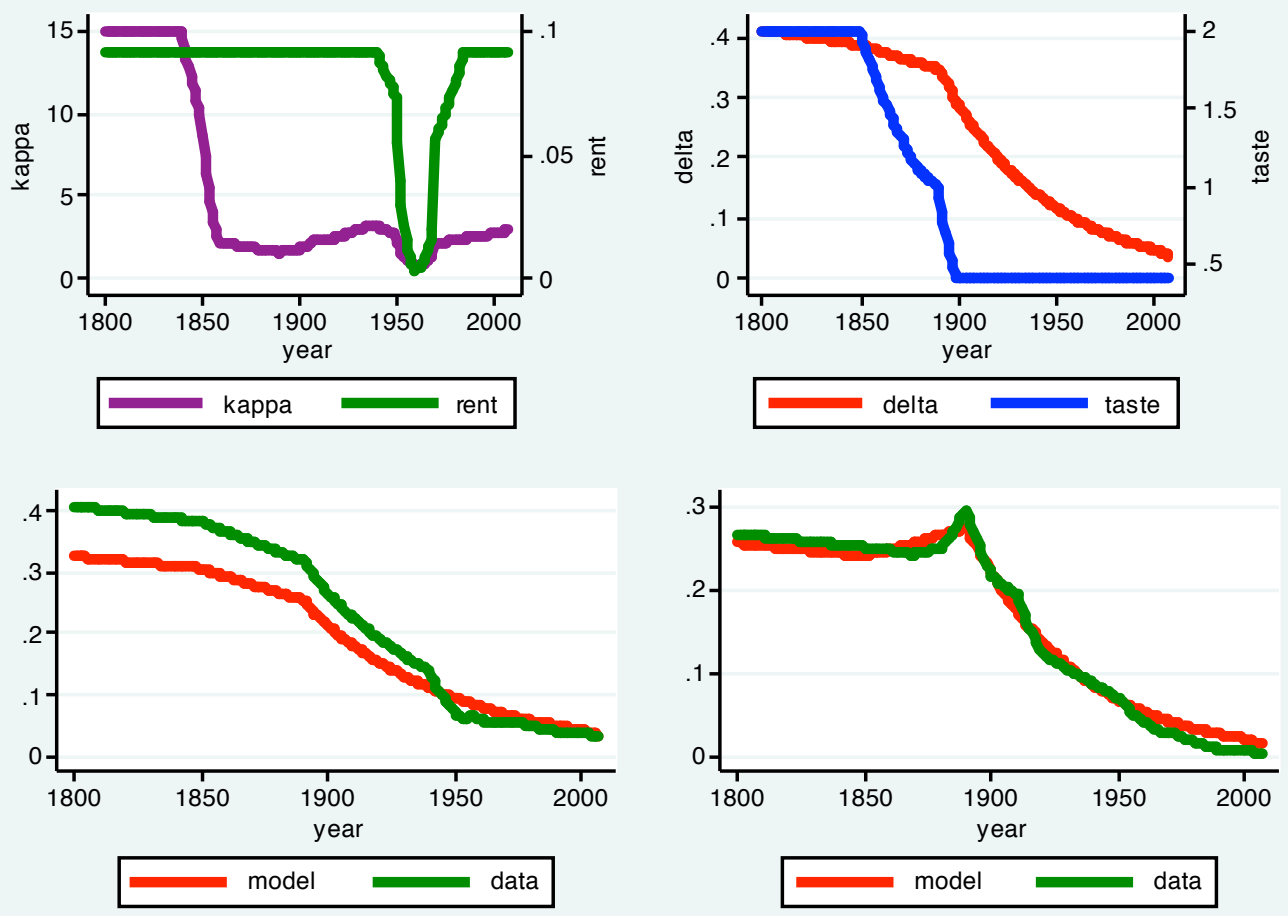

Figure 25: Rents, kappa, Taste Parameter $m u$ and Mortality: : Austria 

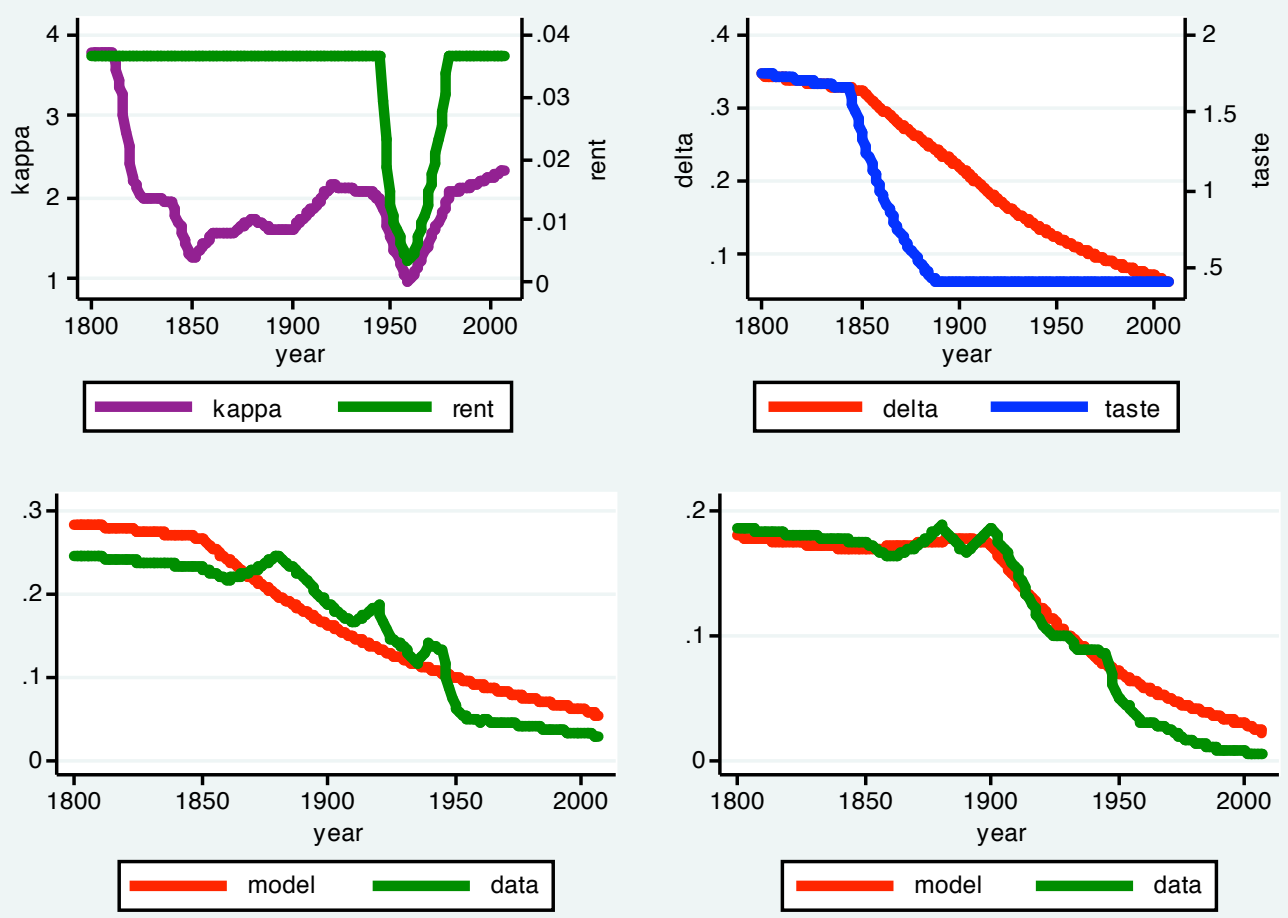

Figure 26: Rents, kappa, Taste Parameter mu and Mortality: : Belgium
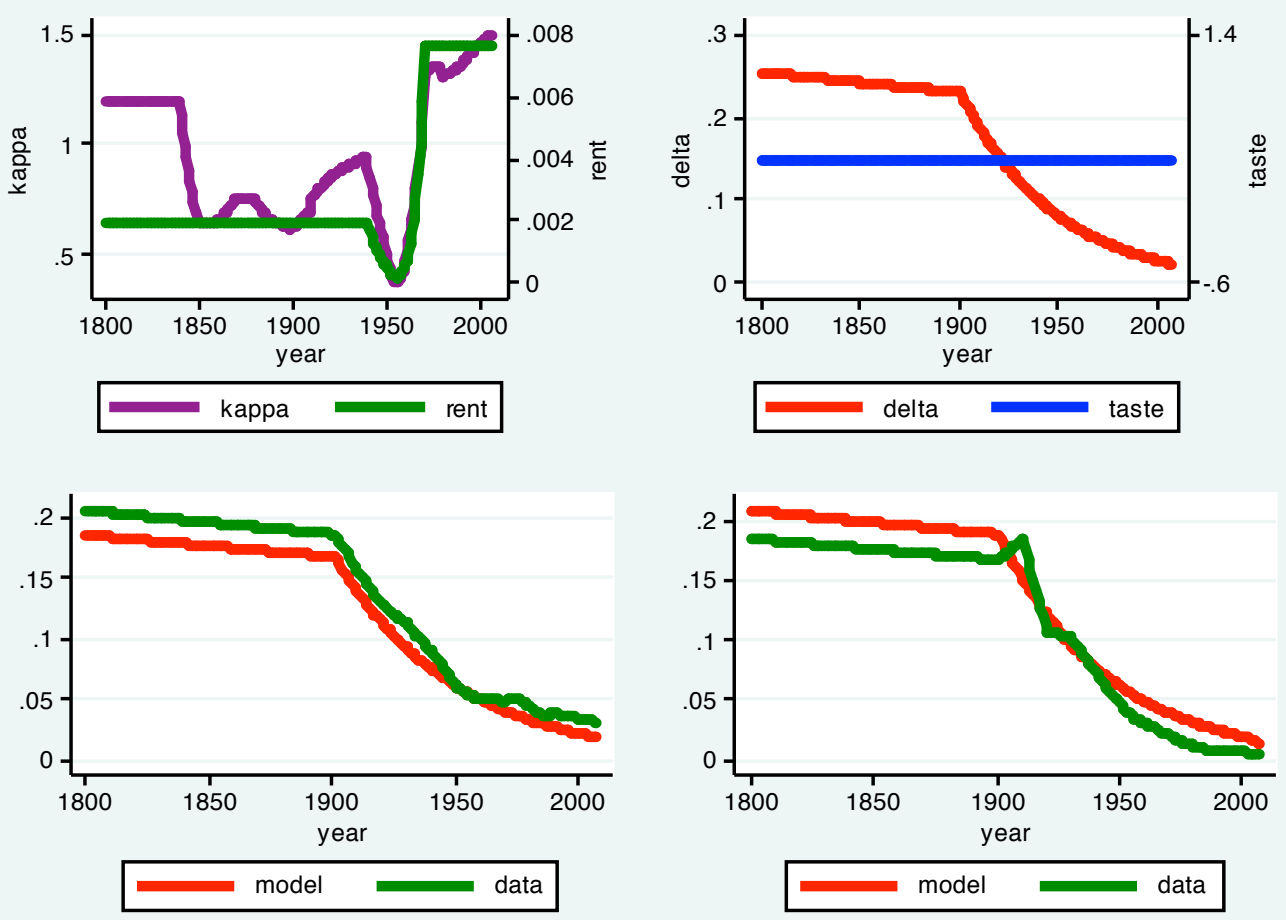

Figure 27: Rents, kappa, Taste Parameter $m u$ and Mortality: : Canada 

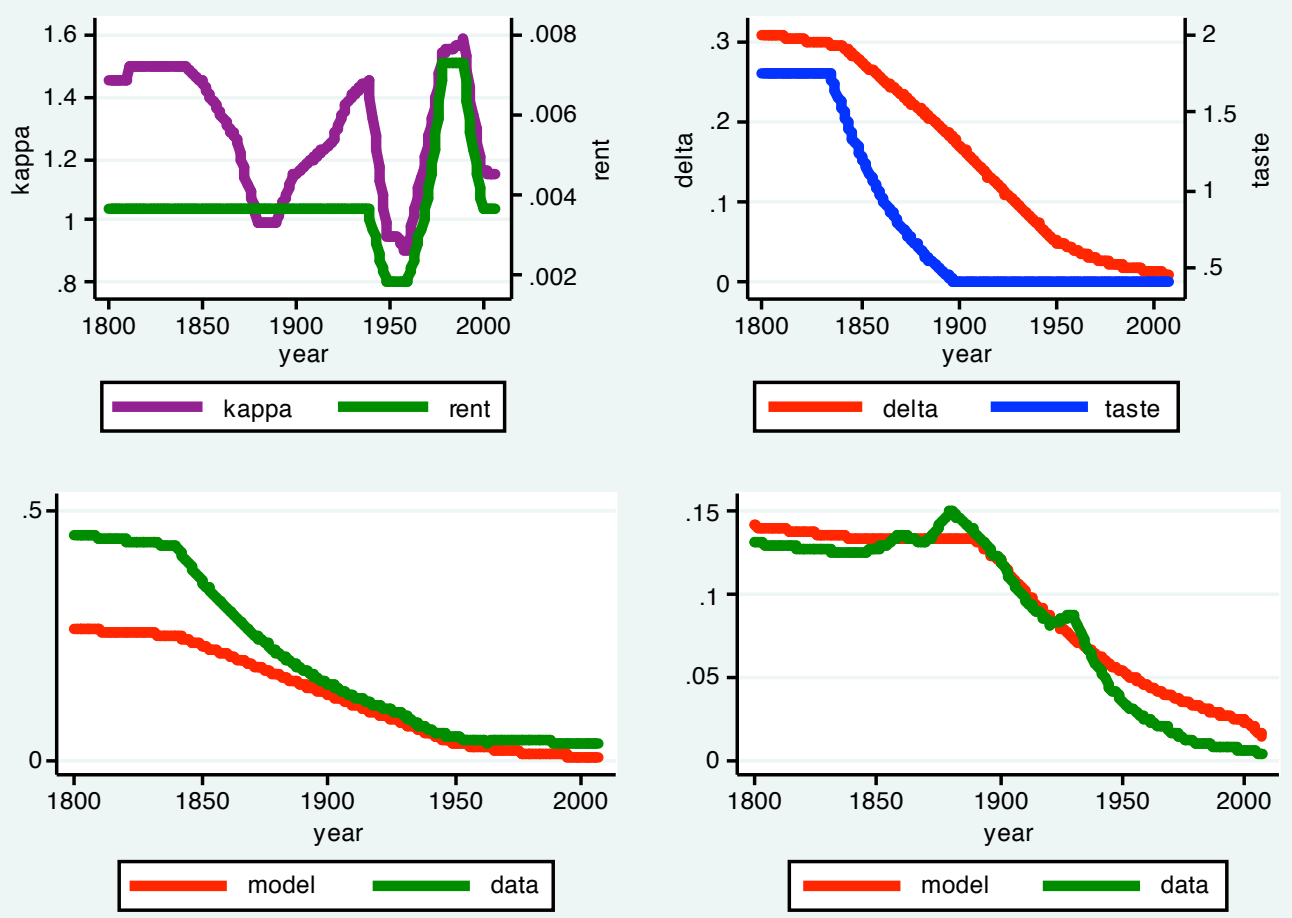

Figure 28: Rents, kappa, Taste Parameter mu and Mortality: : Denmark
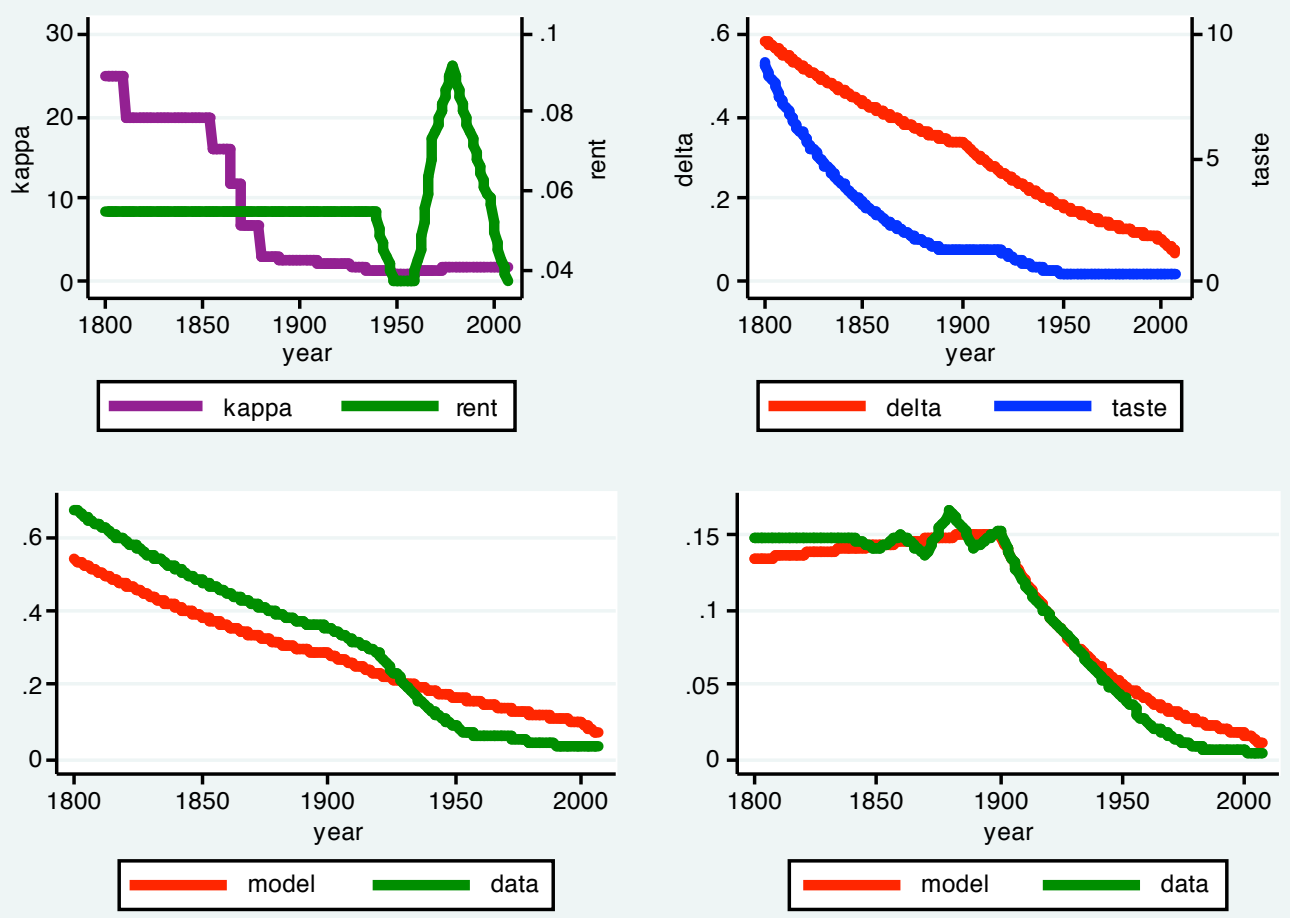

Figure 29: Rents, kappa, Taste Parameter $m u$ and Mortality: : Finland 

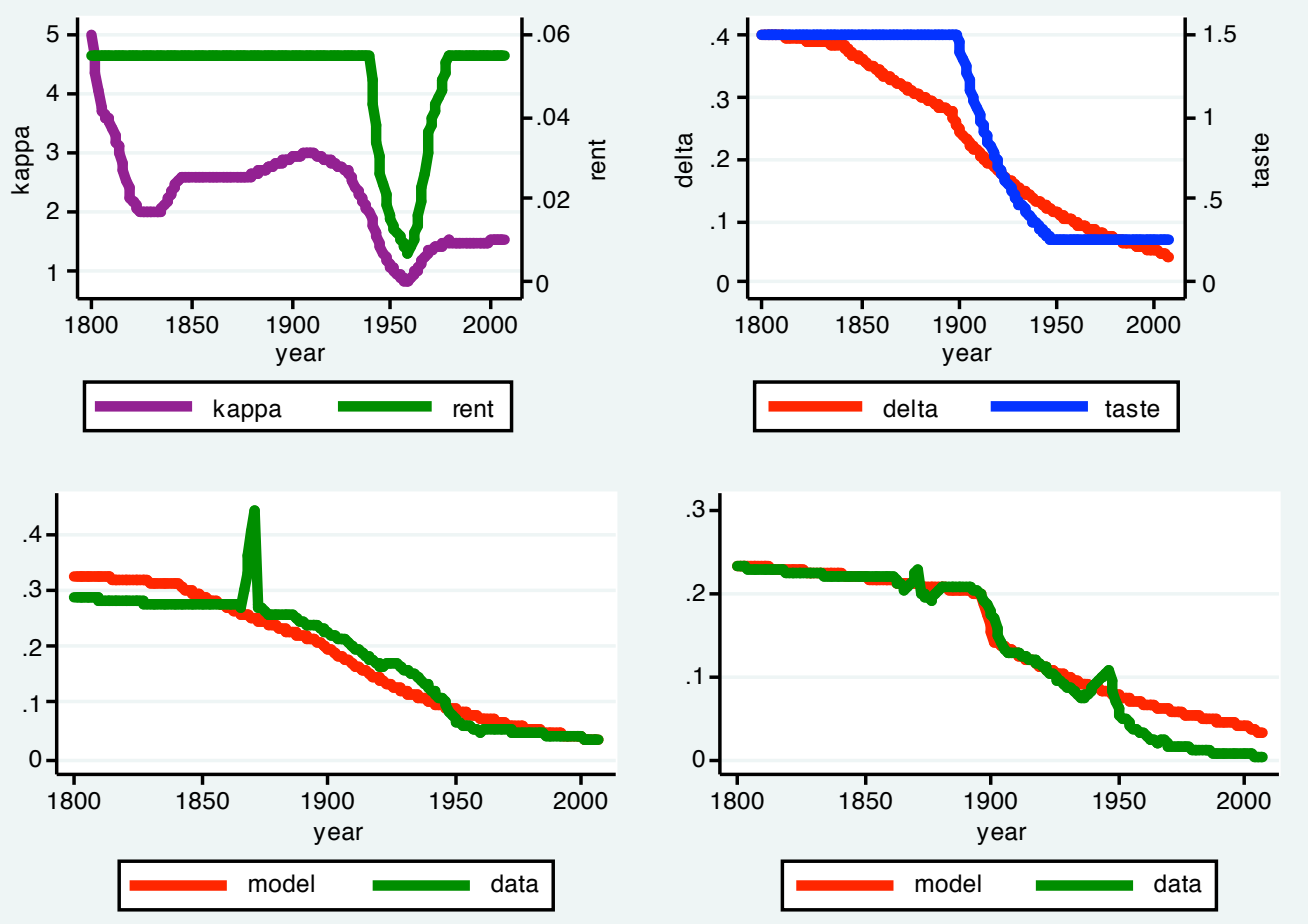

Figure 30: Rents, kappa, Taste Parameter $m u$ and Mortality: : France 

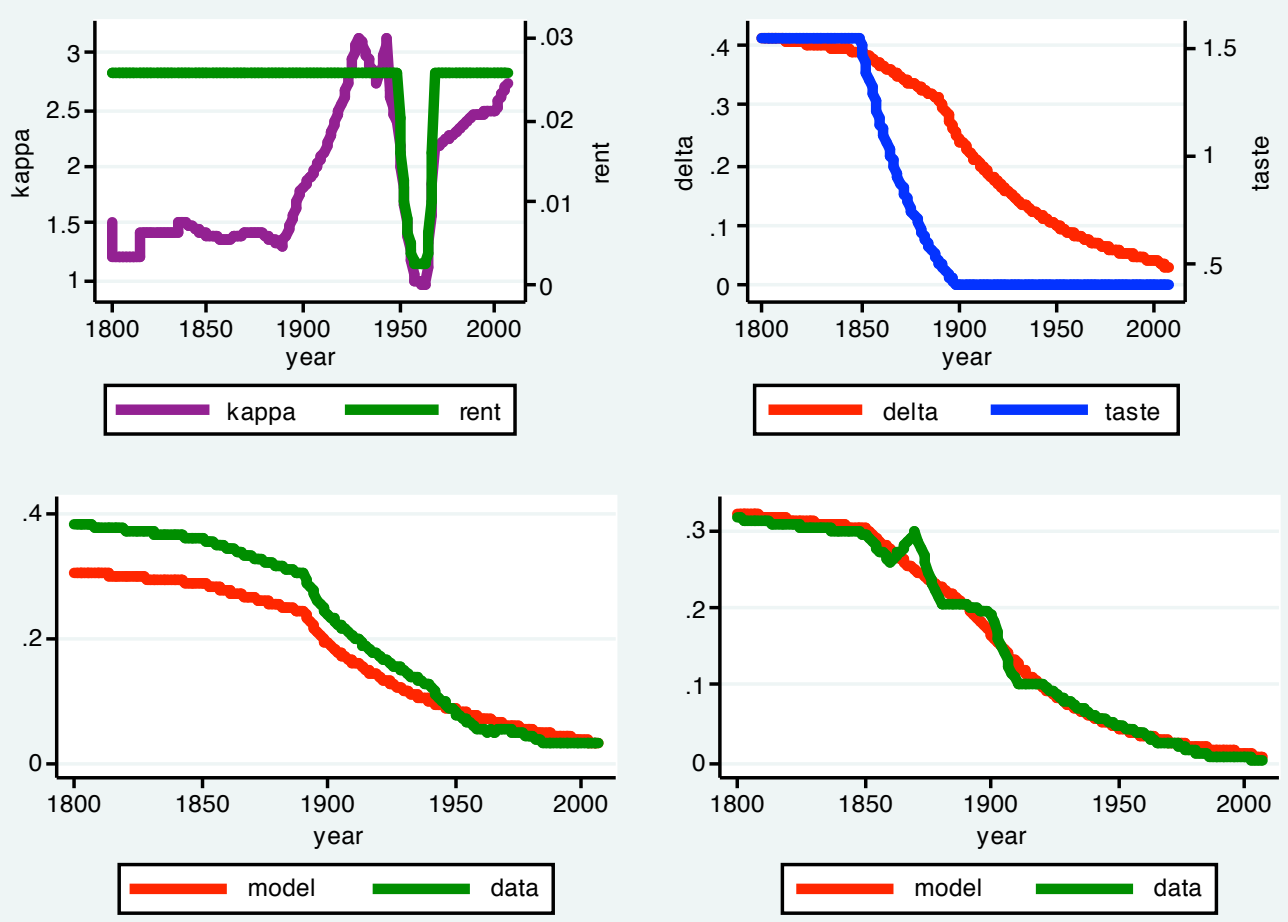

Figure 31: Rents, kappa, Taste Parameter $m u$ and Mortality: : Germany
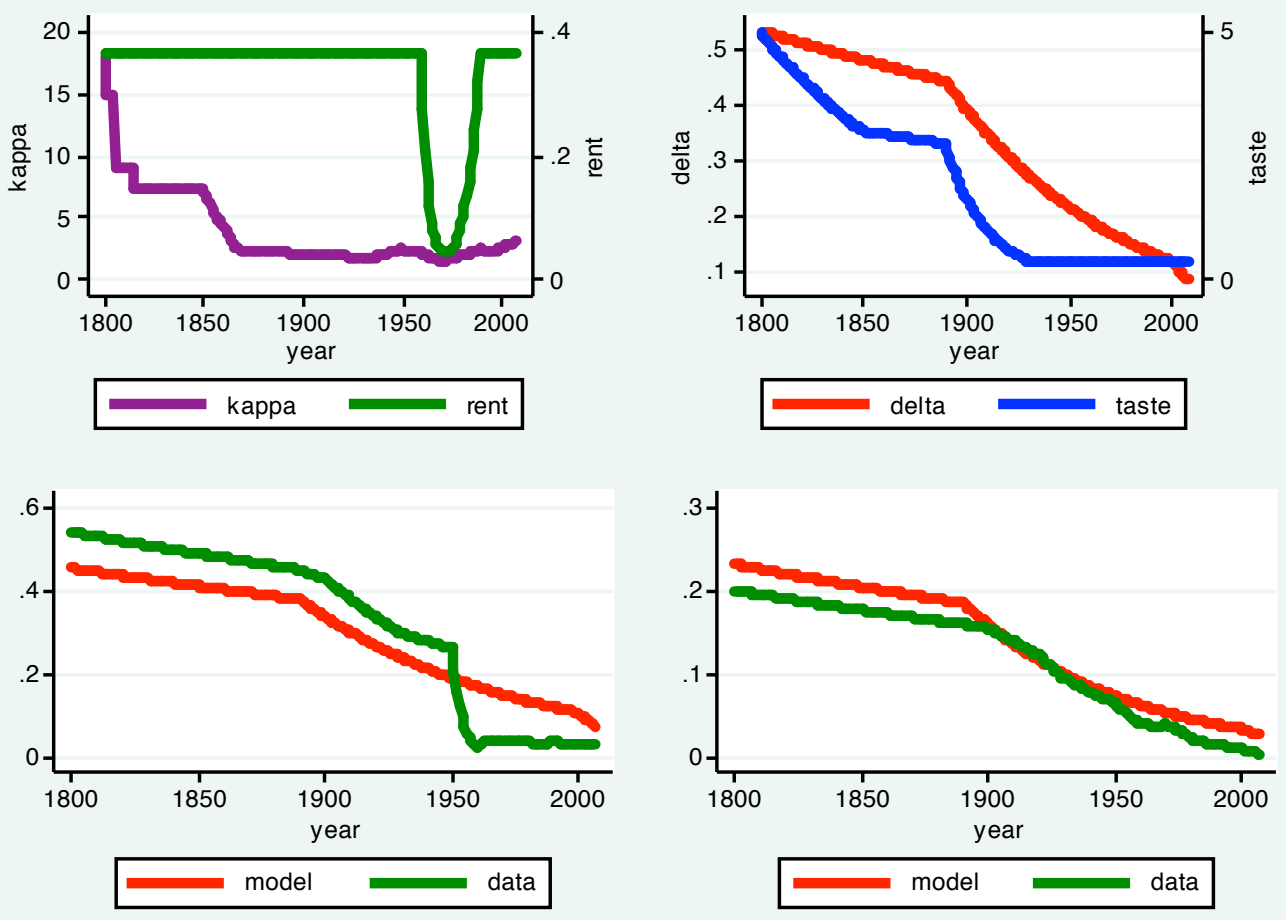

Figure 32: Rents, kappa, Taste Parameter $m u$ and Mortality: : Greece 

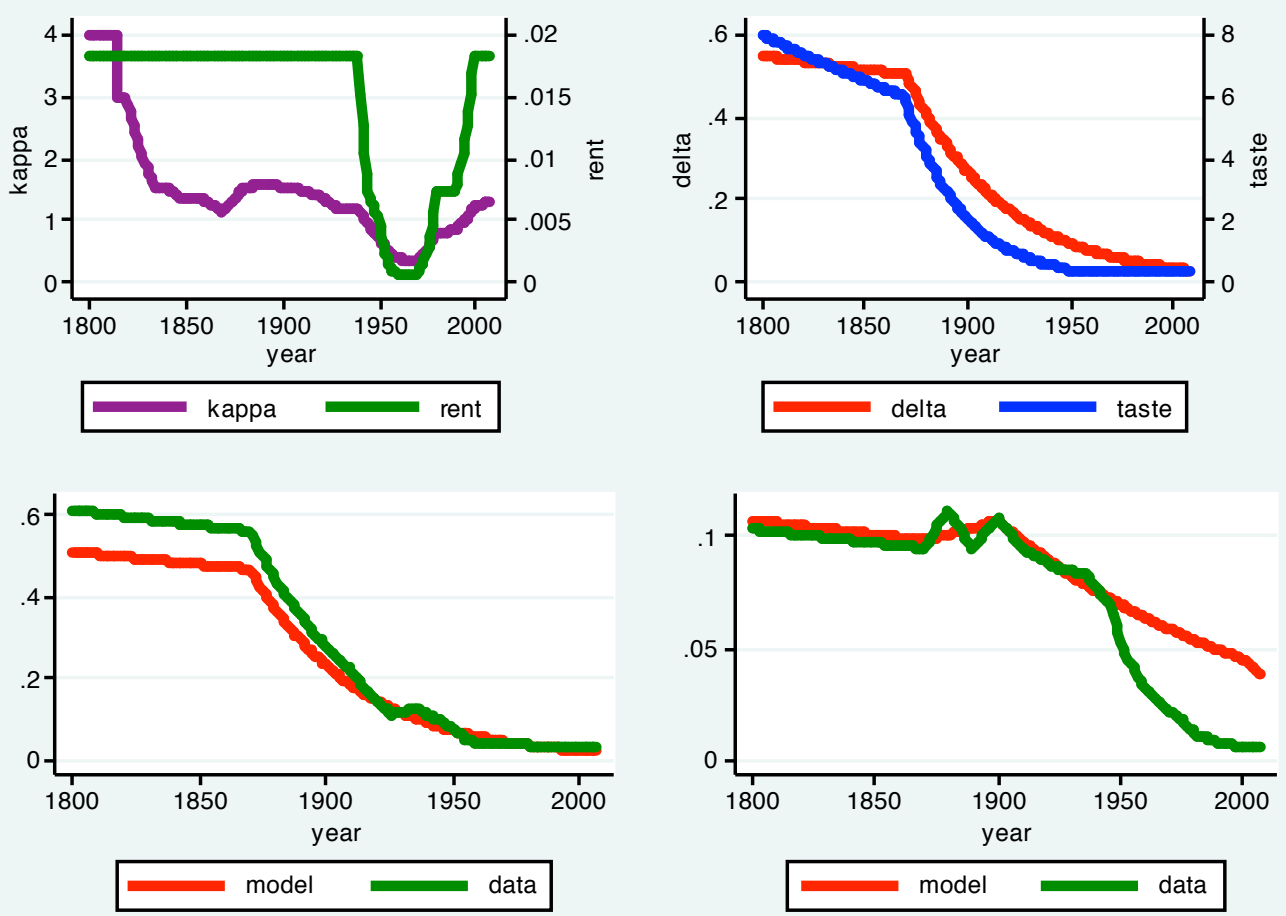

Figure 33: Rents, kappa, Taste Parameter mu and Mortality: : Ireland
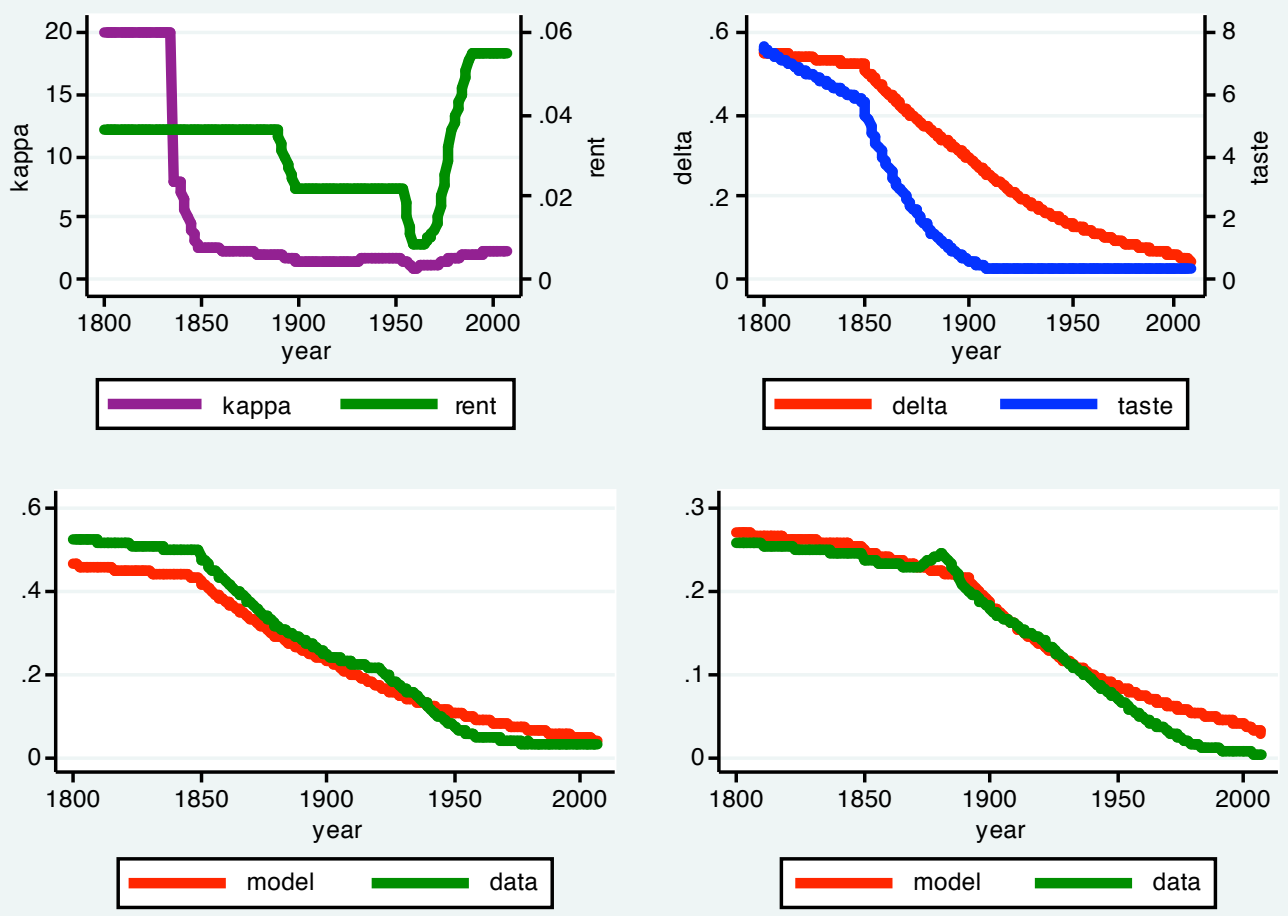

Figure 34: Rents, kappa, Taste Parameter $m u$ and Mortality: : Italy 

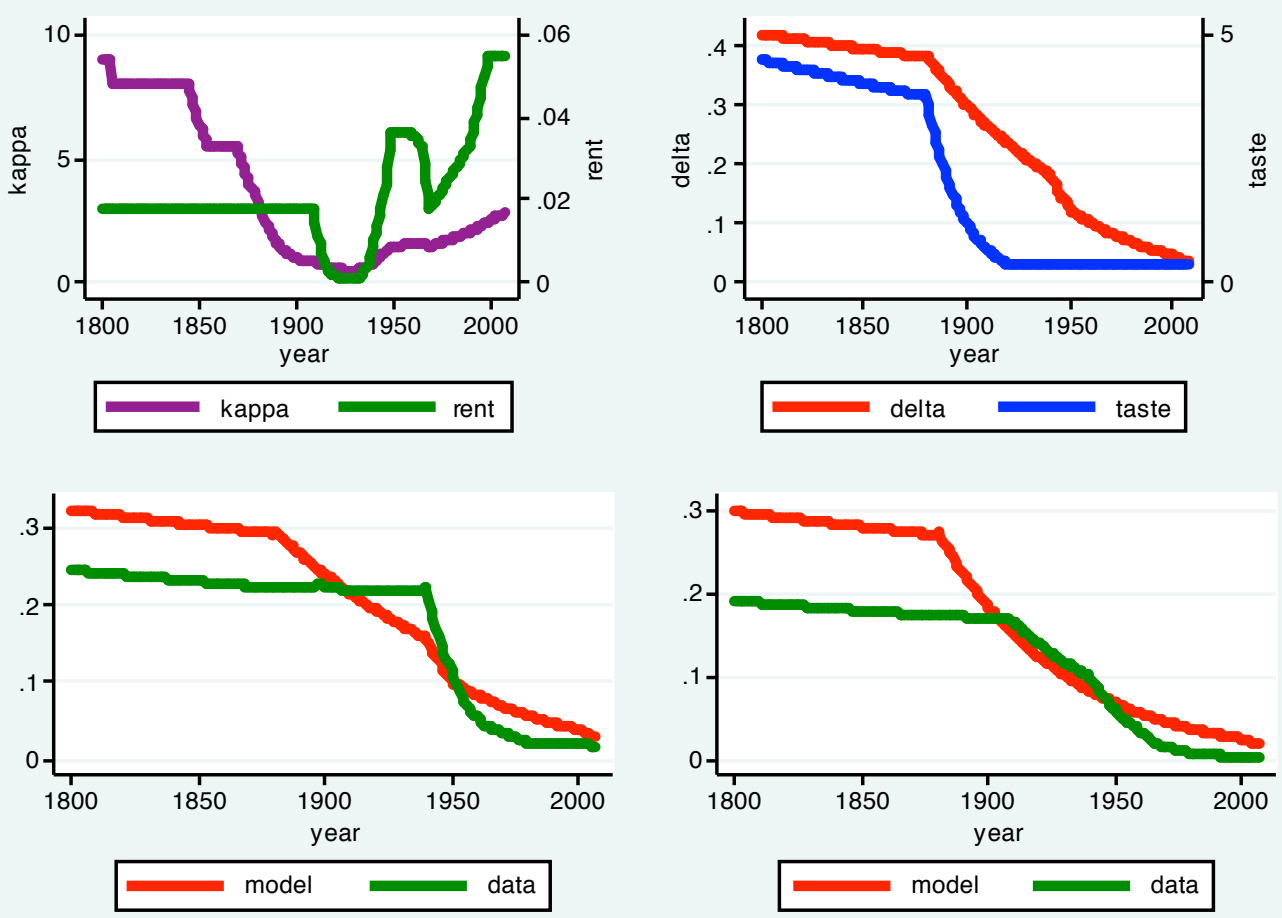

Figure 35: Rents, kappa, Taste Parameter mu and Mortality: : Japan
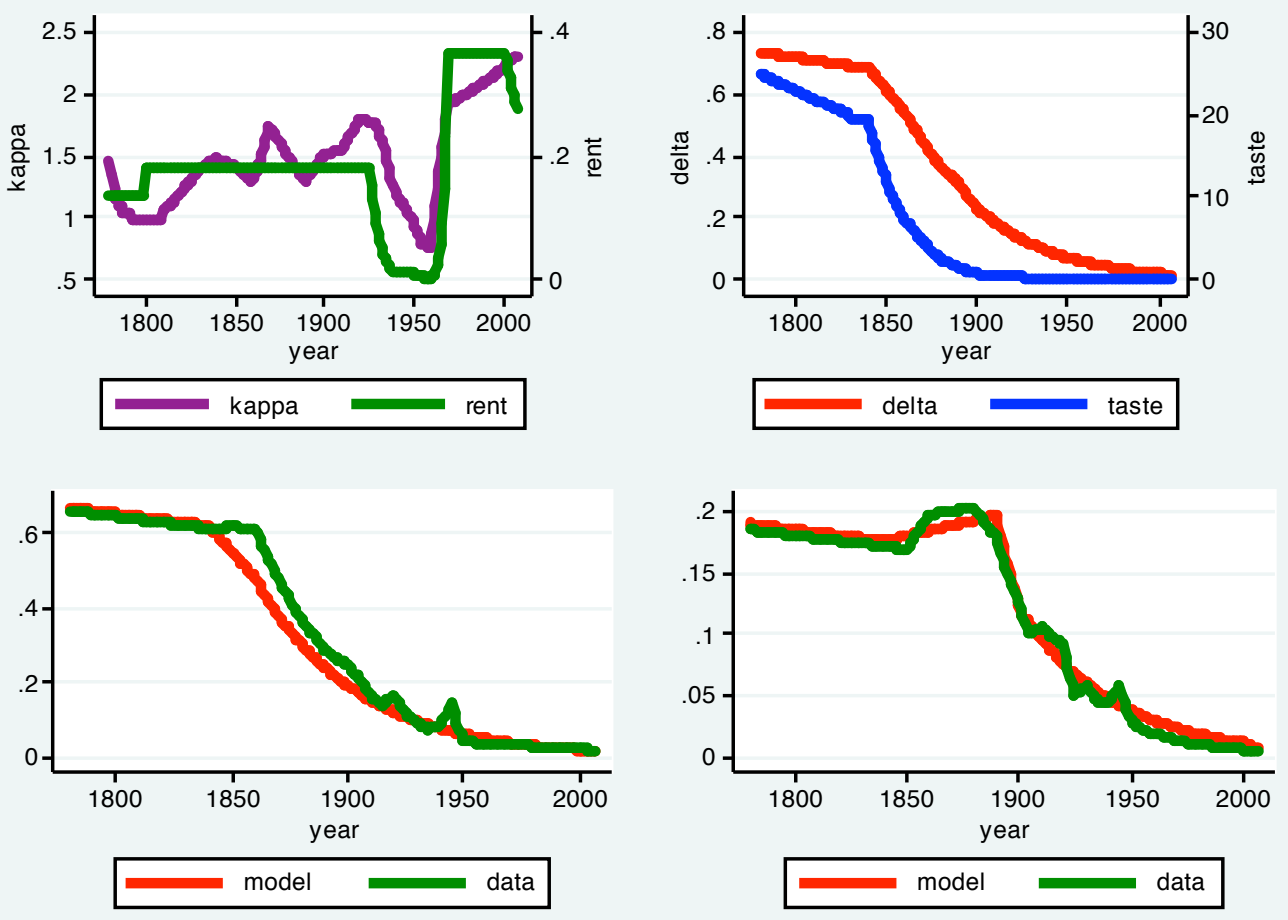

Figure 36: Rents, kappa, Taste Parameter mu and Mortality: : Netherlands 

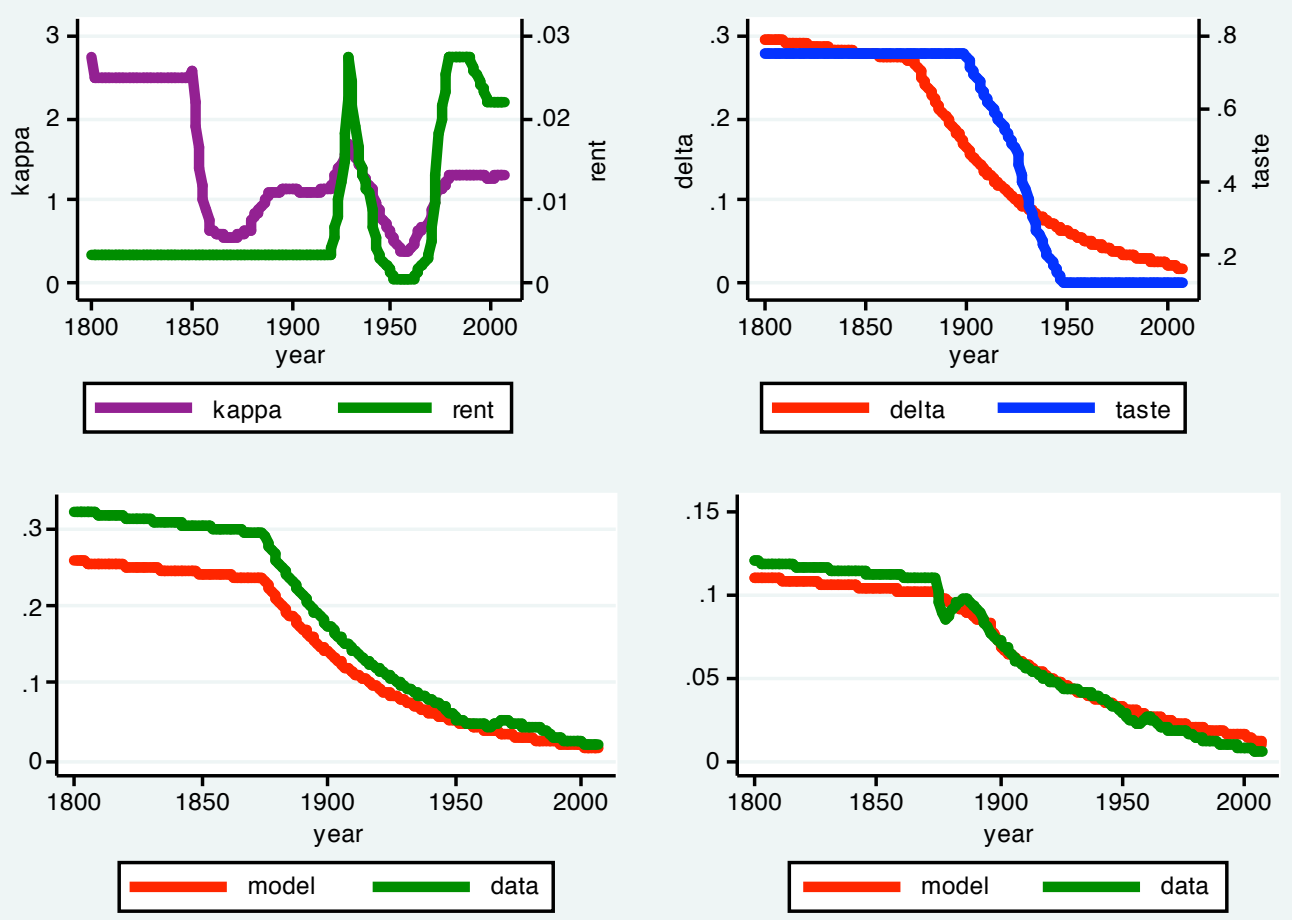

Figure 37: Rents, kappa, Taste Parameter $m u$ and Mortality: : New Zealand
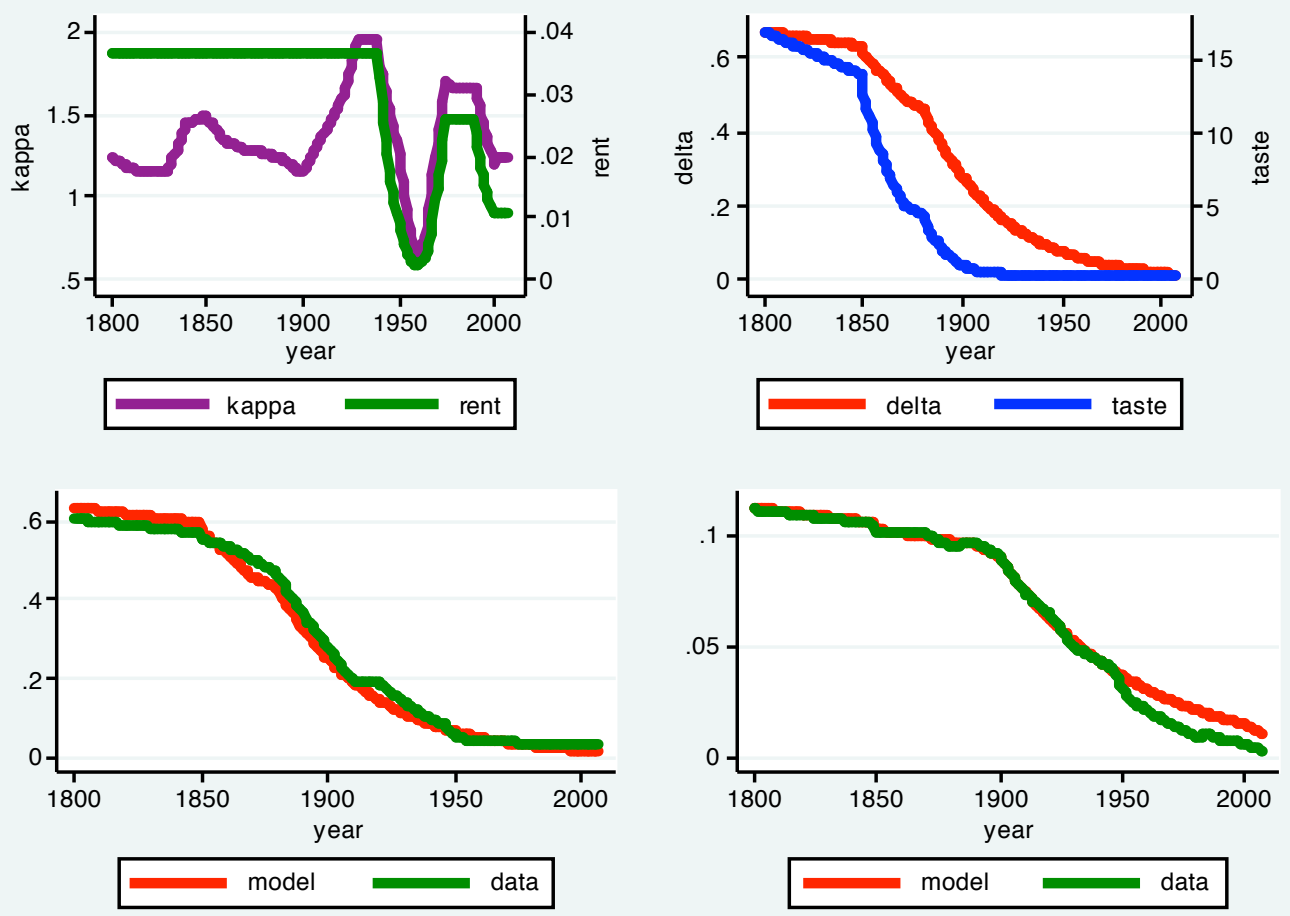

Figure 38: Rents, kappa, Taste Parameter $m u$ and Mortality: : Norway 

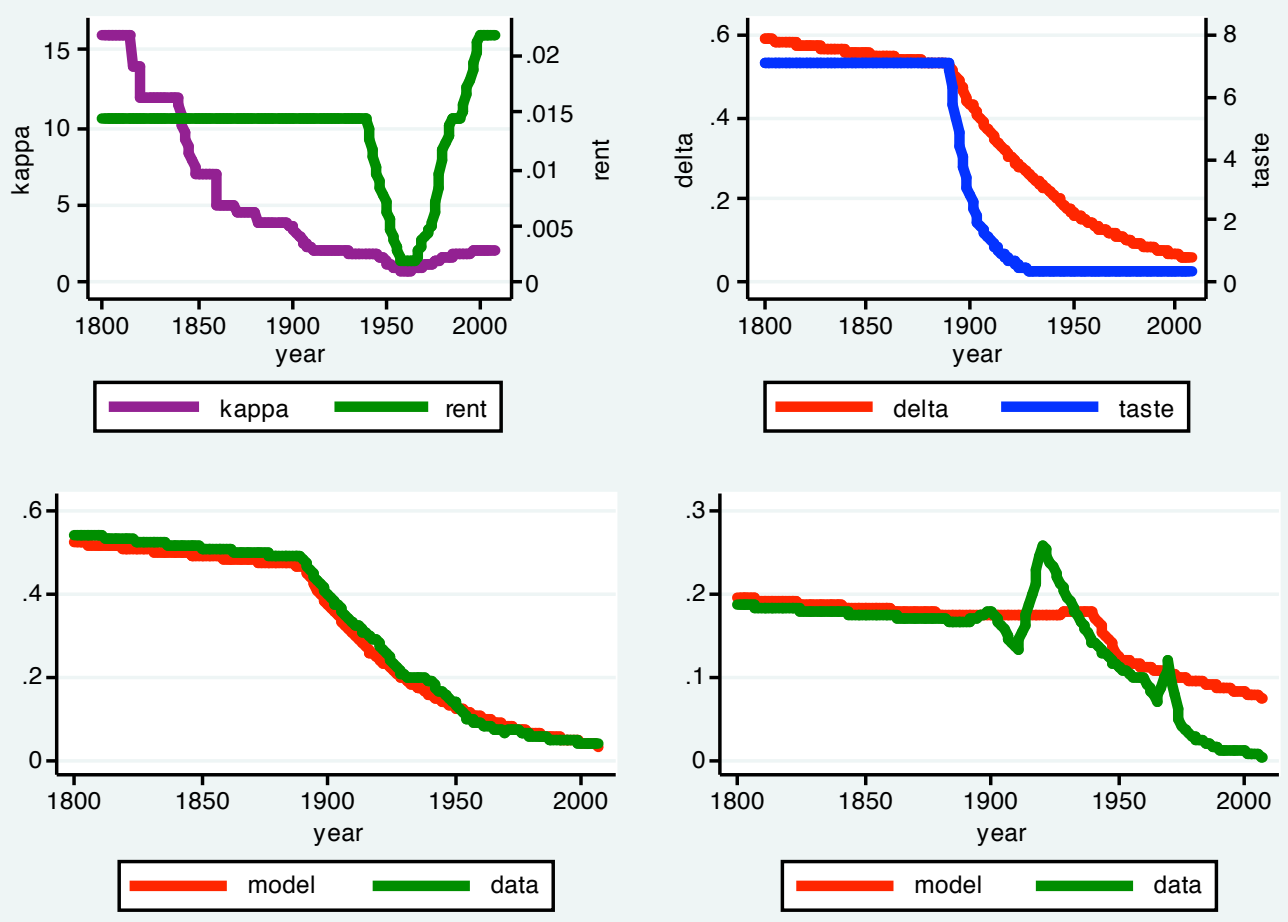

Figure 39: Rents, kappa, Taste Parameter $m u$ and Mortality: : Portugal
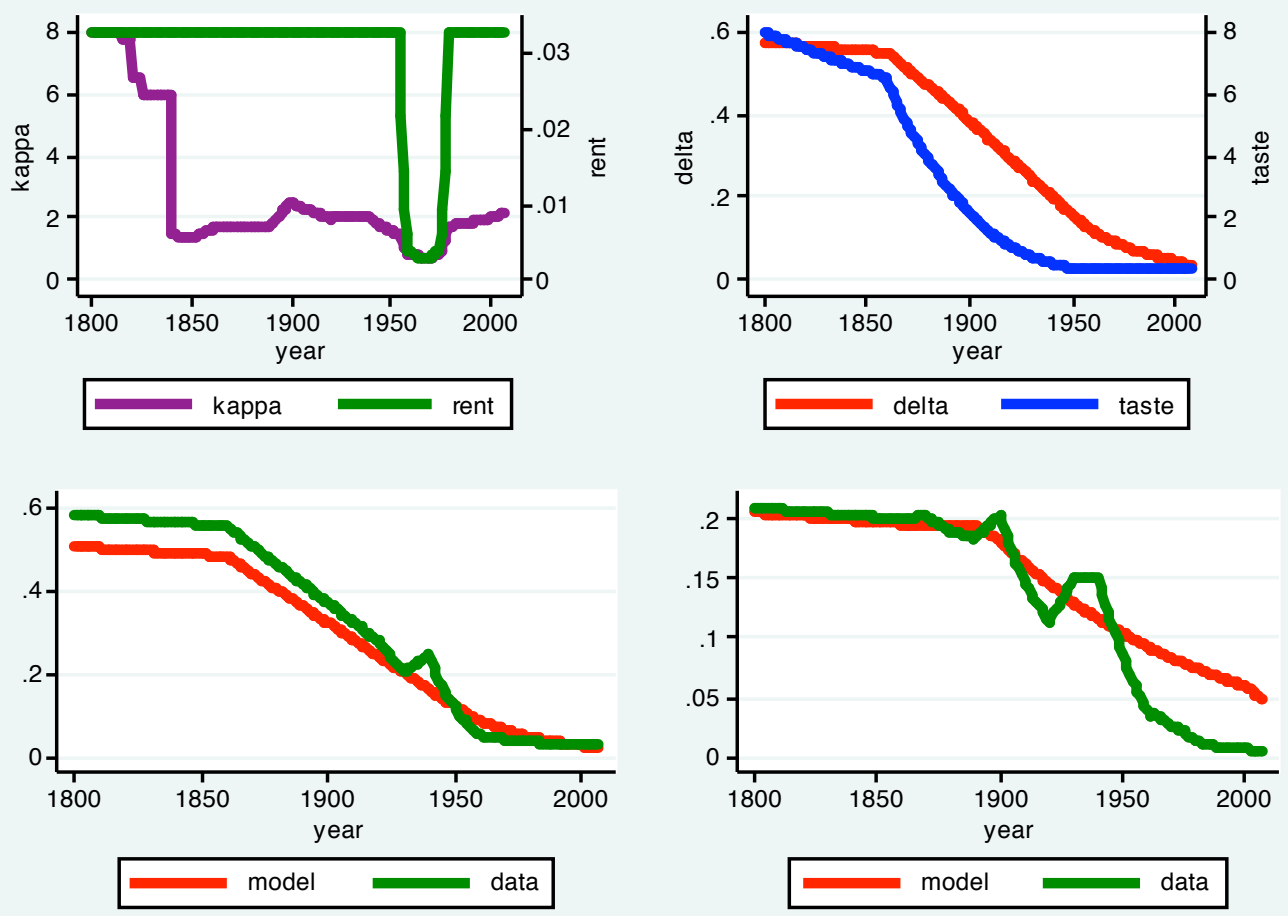

Figure 40: Rents, kappa, Taste Parameter $m u$ and Mortality: : Spain 

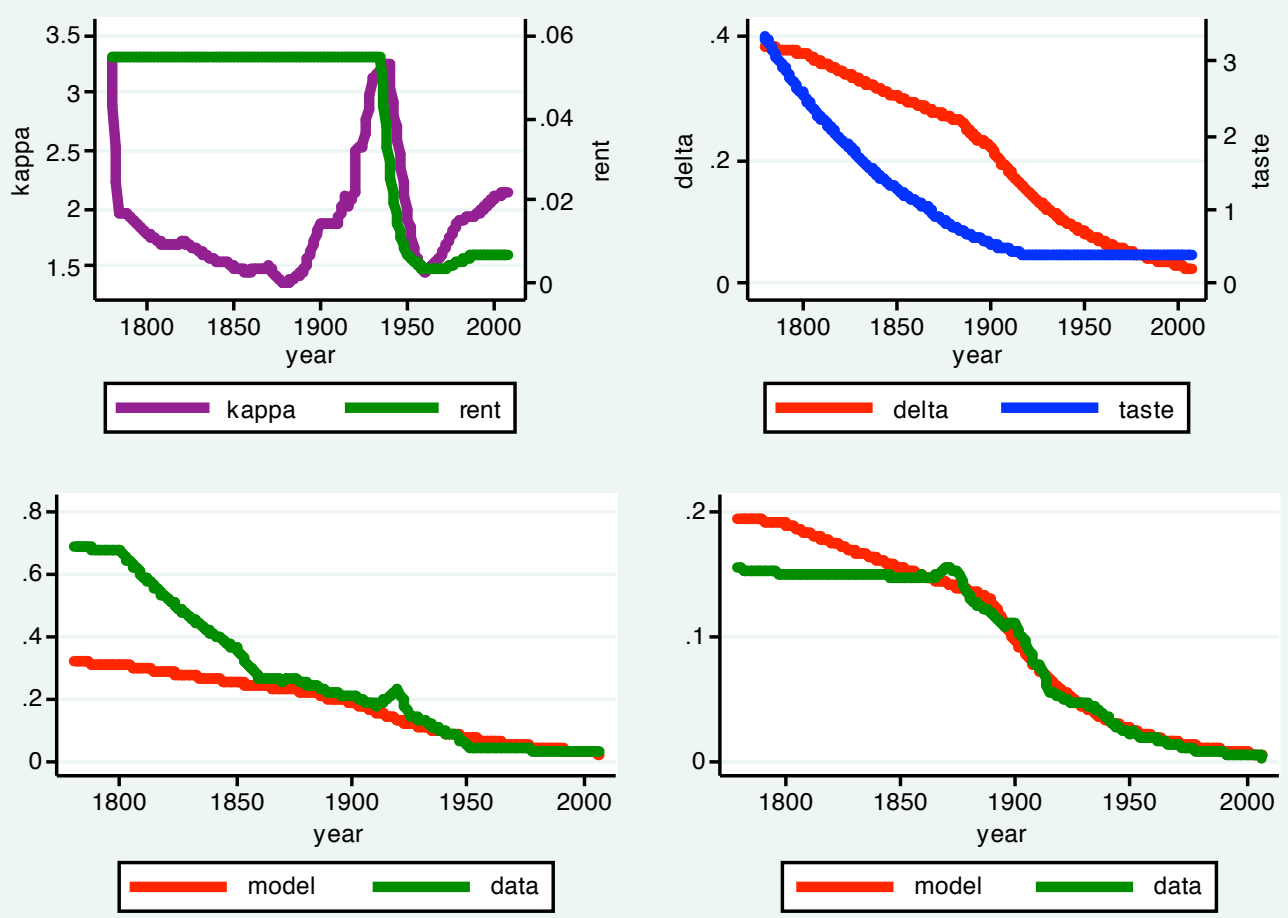

Figure 41: Rents, kappa, Taste Parameter $m u$ and Mortality: : Sweden
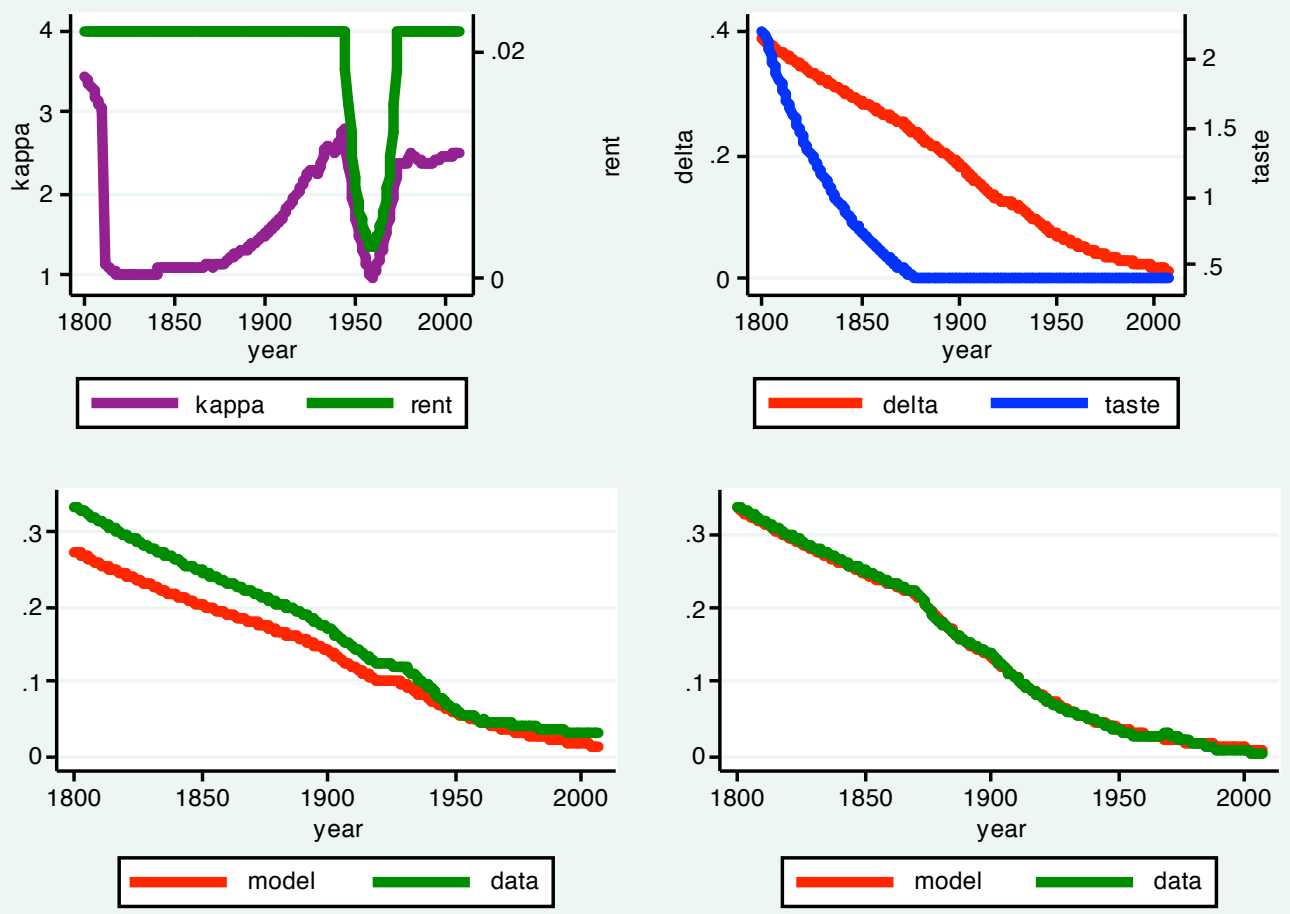

Figure 42: Rents, kappa, Taste Parameter $m u$ and Mortality: : Switzerland 

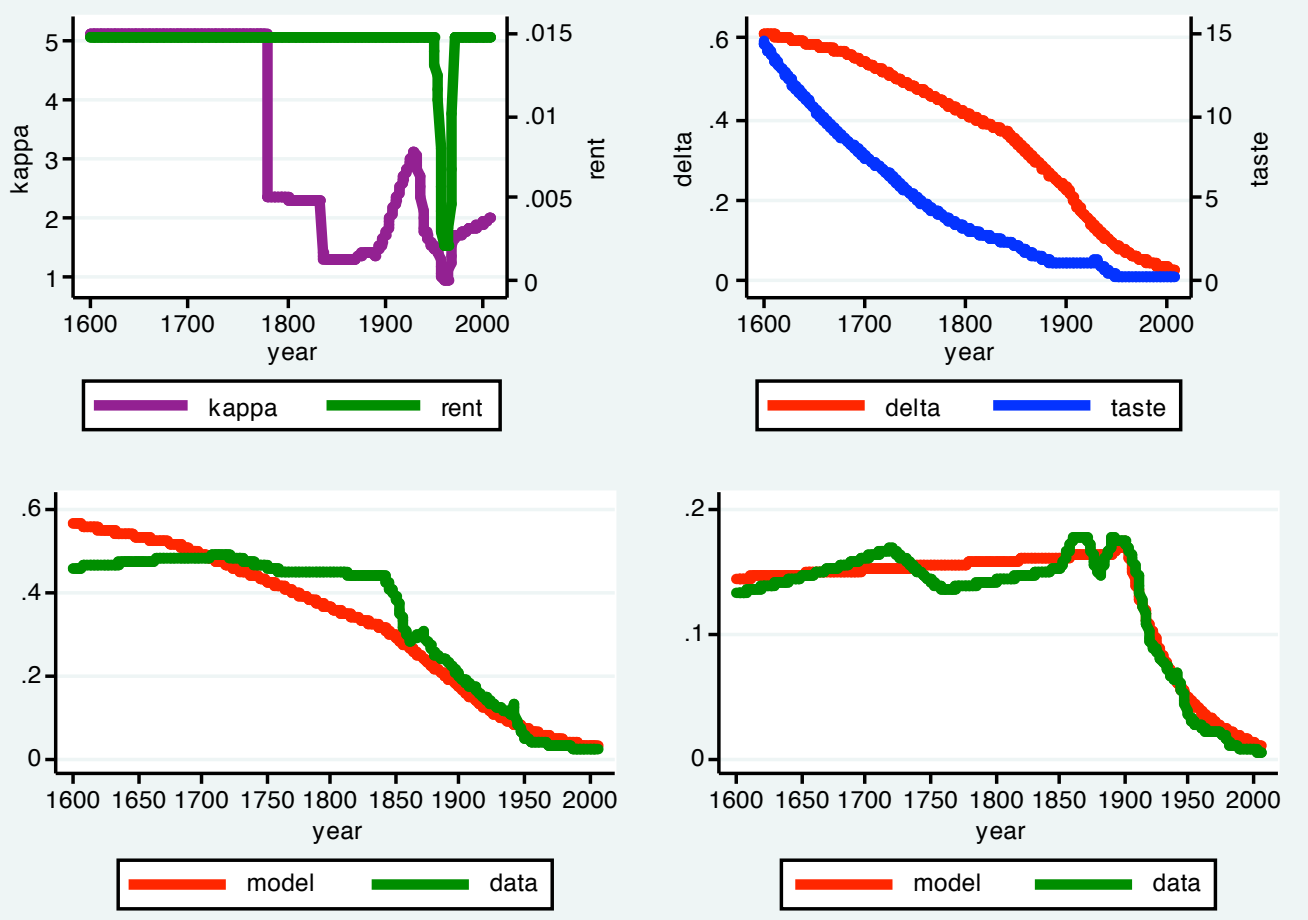

Figure 43: Rents, kappa, Taste Parameter $m u$ and Mortality: : United Kingdom 
Table 1: Pooled Regressions of Actual Observations on Model Solutions

\begin{tabular}{|c|c|c|c|c|c|c|c|c|}
\hline & \multicolumn{4}{|c|}{ fertility } & \multicolumn{4}{|c|}{ schooling } \\
\hline & base & $\nu_{t}$ & $\nu_{t} \mathrm{r}_{t}$ & $\nu_{t} \mathrm{r}_{t} \kappa_{t}$ & base & $\nu_{t}$ & $\nu_{t} \mathrm{r}_{t}$ & $\nu_{t} \mathrm{r}_{t} \kappa_{t}$ \\
\hline \multirow[t]{2}{*}{$\beta$} & $0.3593^{* * *}$ & $0.9588^{* * *}$ & $1.0063^{* * *}$ & $1.0152^{* * *}$ & $0.2087^{* * *}$ & $0.7723^{* * *}$ & $0.8612^{* * *}$ & $0.9967^{* * *}$ \\
\hline & $(0.0210)$ & $(0.0166)$ & $(0.0135)$ & $(0.0132)$ & $(0.0145)$ & $(0.0345)$ & $(0.0425)$ & $(0.0040)$ \\
\hline \multirow[t]{2}{*}{$\alpha$} & $2.0440 * * *$ & $0.1912^{* * *}$ & -0.0402 & -0.0248 & $4.0785^{* * *}$ & $2.0061^{* * *}$ & $1.8315^{* * *}$ & 0.0110 \\
\hline & $(0.0659)$ & $(0.0513)$ & $(0.0412)$ & $(0.0402)$ & $(0.1998)$ & $(0.2548)$ & $(0.2176)$ & $(0.0280)$ \\
\hline$N$ & 507 & 507 & 507 & 507 & 448 & 448 & 448 & 448 \\
\hline $\bar{R}^{2}$ & .7530 & .9369 & .9696 & .9687 & .7284 & .7775 & .7391 & .9972 \\
\hline \multirow[t]{3}{*}{$\mathrm{p}$} & .0000 & 0.0000 & .2455 & .2012 & .0000 & .0000 & .0000 & .6276 \\
\hline & \multicolumn{4}{|c|}{ young schooling } & \multicolumn{4}{|c|}{$\overline{l n} \ln$ (income) } \\
\hline & base & $\nu_{t}$ & $\nu_{t} \mathrm{r}_{t}$ & $\nu_{t} \mathrm{r}_{t} \kappa_{t}$ & base & $\nu_{t}$ & $\nu_{t} \mathrm{r}_{t}$ & $\nu_{t} \mathrm{r}_{t} \kappa_{t}$ \\
\hline \multirow[t]{2}{*}{$\beta$} & $0.1742^{* * *}$ & $0.5565^{* * *}$ & $0.6100^{* * *}$ & $0.9329 * * *$ & $0.9736^{* * *}$ & $1.0312^{* * *}$ & $1.0376^{* * *}$ & $0.9876^{* * *}$ \\
\hline & $(0.0141)$ & $(0.0252)$ & $(0.0 .0287)$ & $(0.0116)$ & $(0.0075)$ & $(0.0054)$ & $(0.0055)$ & $(0.0052)$ \\
\hline \multirow[t]{2}{*}{$\alpha$} & $4.8705^{* * *}$ & $3.4779 * * *$ & $3.3863^{* * *}$ & $-0.2088^{* *}$ & $0.1254^{*}$ & $-0.4506^{* * *}$ & $-0.5049^{* * *}$ & -0.0586 \\
\hline & $(0.2670)$ & $(0.2788)$ & $(0.2770)$ & $(0.1050)$ & $(0.0720)$ & $(0.0537)$ & $(0.0534)$ & $(0.0500)$ \\
\hline$N$ & 448 & 448 & 448 & 448 & 440 & 440 & 440 & 440 \\
\hline $\bar{R}^{2}$ & .7166 & .7682 & .7843 & .9752 & .9023 & .9060 & .9051 & .9126 \\
\hline $\mathrm{p}$ & .0000 & .0000 & .0000 & .0000 & .0000 & .0000 & .0000 & .0000 \\
\hline
\end{tabular}

Notes: Table reports results from pooled regressions with errors corrected for panel autocorrelation and Prais-Winsten heteroskedastic error correction. The final row, marked $\mathrm{p}$, is the p-value on the null hypothesis that $\beta=1$ and $\alpha=0$. The regressions on $\ln$ (income) contain dummy variables for World War I, for years 1914-1918 inclusive, the Great Depression, for years 1930-1939, and for World War II, for years 1939-1945 inclusive. 
Table 2: Pooled Regressions of Actual Observations on Model Solutions: Education Expenditures and $\kappa$

\begin{tabular}{|c|c|c|c|c|c|c|c|c|}
\hline & \multicolumn{4}{|c|}{$\kappa_{t} \tau_{t}$} & \multicolumn{4}{|c|}{$\kappa_{t}$} \\
\hline & US & US & US & US & US & US & US & US \\
\hline \multirow[t]{2}{*}{$\beta$} & $1.2496^{* * *}$ & $1.1282^{* * *}$ & $1.3649^{* * *}$ & $1.4510^{* * *}$ & $1.0714^{* * *}$ & $0.7413^{* * *}$ & $1.3684^{* * *}$ & $1.0036^{* * *}$ \\
\hline & $(0.0822)$ & $(0.1631)$ & $(0.0494)$ & $(0.1528)$ & $(0.1809)$ & $(0.1467)$ & $(0.1246)$ & $(0.3063)$ \\
\hline \multirow[t]{2}{*}{$\alpha$} & -0.0171 & $-0.0237^{* *}$ & $-0.0462^{* * *}$ & $-0.0466^{* * *}$ & 0.0847 & 0.0696 & $-0.2981^{* *}$ & -0.1226 \\
\hline & $(0.0187)$ & $(0.0117)$ & $(0.0118)$ & $(0.0112)$ & $(0.2166)$ & $(0.1081)$ & $(0.1474)$ & $(0.2247)$ \\
\hline $20^{t h}$ century & no & yes & no & yes & no & yes & no & yes \\
\hline baby boom & no & no & yes & yes & no & no & yes & yes \\
\hline$N$ & 49 & 49 & 49 & 49 & 49 & 49 & 49 & 49 \\
\hline $\bar{R}^{2}$ & .8507 & .8596 & .8996 & .9015 & .5846 & .6987 & .6858 & .7131 \\
\hline \multirow[t]{3}{*}{$\mathrm{p}$} & .0000 & 0.0000 & .0000 & .0000 & .0000 & .0000 & .0000 & .0000 \\
\hline & \multicolumn{4}{|c|}{$\kappa_{t} \tau_{t}$} & \multicolumn{4}{|c|}{$\kappa_{t}$} \\
\hline & \multicolumn{4}{|c|}{ all 21 countries } & \multicolumn{4}{|c|}{ all 21 countries } \\
\hline \multirow[t]{2}{*}{$\beta$} & $0.4384^{* * *}$ & $0.3085^{* * *}$ & $0.4688^{* * *}$ & $0.3275^{* * *}$ & $0.3201^{* * *}$ & $0.3230^{* * *}$ & $0.4067^{* * *}$ & $0.4084^{* * *}$ \\
\hline & $(0.0528)$ & $(0.0567)$ & $(0.0541)$ & $(0.0616)$ & $(0.0981)$ & $(0.0980)$ & $(0.1013)$ & $(0.1007)$ \\
\hline \multirow[t]{2}{*}{$\alpha$} & $0.0878^{* * *}$ & $0.0504^{* * *}$ & $0.0757^{* * *}$ & $0.0484^{* * *}$ & $1.0915^{* * *}$ & $1.0628^{* * *}$ & $0.8861^{* * *}$ & $0.9128^{* * *}$ \\
\hline & $(0.0125)$ & $(0.0139)$ & $(0.0134)$ & $(0.0140)$ & $(0.1528)$ & $(0.2212)$ & $(0.1664)$ & $(0.2197)$ \\
\hline$N$ & 282 & 282 & 282 & 282 & 282 & 282 & 282 & 282 \\
\hline $\bar{R}^{2}$ & .4896 & .5417 & .5028 & .5432 & .2737 & .2630 & .2466 & .2466 \\
\hline $\mathrm{p}$ & .0000 & .0000 & .0000 & .0000 & .0000 & .0000 & .0000 & .0000 \\
\hline
\end{tabular}

Notes: Table reports results from pooled regressions with errors corrected for panel autocorrelation and Prais-Winsten heteroskedastic error correction. The final row, marked $\mathrm{p}$, is the $\mathrm{p}$-value on the null hypothesis that $\beta=1$ and $\alpha=0$. 
Table 3: Preference Parameters, $\beta, \nu$, and Education Efficiency, $\mu$

\begin{tabular}{lrrr}
\hline \hline country & $\beta$ & $\nu$ & $\mu$ \\
\hline Australia & .36 & .400 & .0850 \\
Austria & .18 & .400 & .0850 \\
Belgium & .18 & .400 & .0900 \\
Canada & .27 & .400 & .0950 \\
Denmark & .30 & .400 & .1000 \\
Finland & .18 & .400 & .0850 \\
France & .18 & .250 & .0750 \\
Germany & .18 & .400 & .0950 \\
Greece & .18 & .400 & .0900 \\
Ireland & .63 & .400 & .0850 \\
Italy & .18 & .400 & .0850 \\
Japan & .36 & .400 & .0950 \\
Netherlands & .75 & .200 & .1150 \\
New Zealand & .54 & .125 & .1000 \\
Notes: Table reports stationary values of $\beta$ \\
schooling time, $\mu$.
\end{tabular}

